Working Paper/Document de travail 2013-12

\title{
Jump-Diffusion Long-Run Risks Models, Variance Risk Premium and Volatility Dynamics
}

by Jianjian Jin 
Bank of Canada Working Paper 2013-12

April 2013

\title{
Jump-Diffusion Long-Run Risks Models, Variance Risk Premium and Volatility Dynamics
}

\author{
by \\ Jianjian Jin \\ Funds Management and Banking Department \\ Bank of Canada \\ Ottawa, Ontario, Canada K1A OG9 \\ jinj@bankofcanada.ca
}

Bank of Canada working papers are theoretical or empirical works-in-progress on subjects in economics and finance. The views expressed in this paper are those of the author. No responsibility for them should be attributed to the Bank of Canada. 


\section{Acknowledgements}

This paper is part of my PhD dissertation at the Department of Economics, Northwestern University. I would like to thank my advisors Torben Andersen, Jonathan Parker, and Viktor Todorov for many discussions. I would also like to thank Briana Chang, Bruno Feunou, Jean-Sébastien Fontaine, Jingling Guan, Lukasz Pomorski and Martin Szydlowski for many insightful discussions. I especially thank Dr. Nicola Fusari for his generous help with the high frequency future data and inspiring discussions. I benefited also from comments from seminar and conference participants at the Federal Reserve Board, the Bank of Canada, and the 2012 European Financial Management Association Annual Meeting. I assume full responsibility for any errors. 


\begin{abstract}
This paper calibrates a class of jump-diffusion long-run risks (LRR) models to quantify how well they can jointly explain the equity risk premium and the variance risk premium in the U.S. financial markets, and whether they can generate realistic dynamics of riskneutral and realized volatilities. I provide evidence that the jump risk in volatility of long run consumption growth is a key component of the equity risk premium and the variance risk premium in financial markets. Moreover, I find that matching the VIX dynamics during the calibration process is crucial when comparing different jump channels. Specifically, a jump-in-growth LRR model generates a good fit of the average variance risk premium, but a poor fit of the dynamics of the VIX or realized stock volatility. In contrast, a jump-in-volatility LRR model generates a smaller variance risk premium but better fits the VIX and the realized stock volatility dynamics. Finally, jump-in-volatility models generate predictability of returns by the variance risk premium that is more consistent with the data.
\end{abstract}

JEL classification: G12, G17

Bank classification: Asset pricing; Economic models

\title{
Résumé
}

L'auteur calibre une classe de modèles de diffusion avec sauts et risques de long terme, afin d'évaluer leur aptitude à générer les primes de risque sur actions et de risque de variance observées dans les marchés financiers américains et des dynamiques des volatilités réalisée et risque-neutre reflétant la réalité. Il démontre que le risque de saut associé à la volatilité de la croissance de la consommation à long terme est une composante clé de ces deux primes. L'auteur constate par ailleurs que reproduire les évolutions de l'indice VIX durant le processus de calibrage est un aspect indispensable de la comparaison des différentes sources de sauts. Plus précisément, les modèles avec sauts dans la croissance anticipée de la consommation répliquent assez bien la prime moyenne liée au risque de variance mais plutôt mal l'évolution de l'indice VIX et de la volatilité réalisée du marché des actions. À l'opposé, les modèles avec sauts dans la volatilité génèrent une prime de risque de variance inférieure à la véritable prime, mais ils reproduisent mieux la dynamique de l'indice VIX et de la volatilité réalisée du marché des actions. Enfin, cette seconde catégorie de modèles explique mieux la capacité de la prime de risque de variance à prédire les rendements du marché des actions, telle qu'elle ressort des données empiriques.

Classification JEL : G12, G17

Classification de la Banque : Évaluation des actifs; Modèles économiques 


\section{Introduction}

The equity-risk-premium and variance-risk-premium puzzles in the U.S. financial markets have generated strong academic and practitioner interest. ${ }^{1}$ There is a fast growing literature on establishing a general equilibrium model with recursive preferences and long-run consumption growth risks to explain the two premiums jointly. Building on this literature, this paper calibrates a class of jump-diffusion long-run risks (LRR) models and quantifies how well they can jointly account for the equity risk premium, the variance risk premium, and realistic dynamics of risk-neutral and realized volatilities.

The models are inspired by, and closely related to, previous LRR studies that generalize the classic Bansal and Yaron (2004) LRR model in order to explain the variance risk premium (see e.g., Drechsler and Yaron, 2010, Shalistovich, 2009, Bollerslev, Tauchen and Zhou, 2009, Zhou and Zhu, 2009, Benzoni, Collin-Dufresne, and Goldstein, 2010, Eraker, 2008). These extensions include a second stochastic volatility factor (multi-factor model), a jump process in long-run expected consumption growth (jump-in-growth), and a jump process in long-run consumption volatility(jump-in-volatility). Although these studies significantly advance our understanding of the fundamental source of the variance risk premium, several questions remain unanswered. First, it is unclear which channel plays the central role in generating the variance risk premium. Second, it is unclear whether the generalized LRR models can also generate realistic dynamics of stock volatility.

Both questions are important. On one hand, determining the channel driving the variance risk premium has important implications for designing proper risk management and investment strategies. ${ }^{2}$ On the other hand, volatility dynamics are key inputs of any asset pricing model. ${ }^{3}$ If a model misspecifies stock volatility dynamics, it is unlikely to describe

\footnotetext{
${ }^{1}$ The variance risk premium is defined as the difference between the variance swap strike and the ex ante realized variance of the underlying stock index. The high return of selling out-of-money index options or straddles is also closely related to the variance risk premium (Egloff, Leippold, and Wu 2010).

${ }^{2}$ Determing the jump channel is also a central topic in the reduced-form option pricing literature (e.g. Pan 2002, Eraker 2004, Chernov, Gallant, Ghysels, Tauchen 2003, and others).

${ }^{3}$ The importance of building a realistic volatility model in order to understand the relationship between volatility and returns and the economic sources of volatility is illustrated in Ghysels, Santa-Clara and Valka-
} 
the empirical relationship between market volatility and equity risk premium and to explain the economic sources of market volatility. The model's application to stock valuation, option pricing and strategic asset allocation will be limited too. Since a LRR model is a general-equilibrium model which connects both time-varying returns and time-varying stock volatility with the uncertainty of the underlying economic fundamentals, matching volatility dynamics is as crucial as matching the mean returns.

This paper directly tackles these two questions by using the Simulated Methods of Moments (SMM) to calibrate a series of continuous-time LRR models. All the LRR models investigated in this paper are within the class of affine models and are closely related to models proposed in Drechsler and Yaron (2011). In particular, they include multi-factor models, single- and multi- factor jump-in-growth models, and single- and multi-factor jumpin-volatility models. ${ }^{4}$ Drechsler and Yaron (2011) and Benzoni et al. (2010) establish models that allow both jump processes. In order to investigate how each jump channel alone can explain the variance risk premium, I also allow only one specific jump channel to be opened in the model.

Moreover, compared to many LRR studies that obtain parameters through trial-anderror calibration, the SMM approach provides a simple and effective calibration of the model whose state variables are latent. It allows one to find the optimal match between the empirical moments and the simulated ones. Finally, for the continuous-time model investigated here, the SMM approach avoids the time-aggregation problem (Bansal et al. 2006).

In addition to the standard sample moments discussed in Bansal and Yaron (2004) and others, I calibrate models based on the lag-1, lag-6 and lag-12 sample autocovariance moments in monthly VIX to capture volatility dynamics. VIX represents the square-root of the expected variance under the risk-neutral measure. The variance and autocovariance moments in VIX help pin down the mean-reverting parameters of the volatility factor(s). In nov (2005) and Engle et al. (2008).

${ }^{4}$ There are extensive studies that show the importance of using reduced-form multifactor volatility models to describe financial markets (see e.g. Chernov et al. 2003, Chacko and Viceira 2003, Engle 1999, Calvet and Fisher 2008, Bates 2000, Duffie et al. 2000, and Feunou et al. 2012) 
order to reduce computational cost, I do not include autocovariance moments in realized stock volatility during the calibration process; however I check how calibrated models match the dynamic feature in realized stock volatility.

As the main conclusion of this paper, I find that a better fit in volatility dynamics is an important reason to favor a jump-in-volatility model over a jump-in-growth LRR model. Overall, all jump models can generate a decent amount of variance risk premium, while maintaining a good fit in other important asset moments matched by the model in Bansal and Yaron (2004). In terms of fitting the variance risk premium, the calibrated jump-in-growth models perform slightly better than the calibrated jump-in-volatility models. However, the calibrated jump-in-growth models tend to poorly fit the unconditional autocorrelation moments in VIX or realized volatility, but a jump-in-volatility model performs much better. All in all, I find that a multi-factor jump-in-volatility LRR model achieves a better balance matching a high variance risk premium and persistent volatility dynamics.

The advantage of a jump-in-volatility model over a jump-in-growth model also has an intuitive economic interpretation. In the jump-in-volatility framework, when the volatility factor jumps up, the market enters into a high volatility period that persists before the volatility factor returns to the long-term average. In contrast, under the jump-in-growth framework, when the expected consumption growth in the long-run jumps down, the asset valuation experiences a one-time downward adjustment while the contemporaneous realized volatility experiences a short-term surge. However, since the volatility factors are not affected by growth jumps, market volatility immediately returns to the normal state in the next period, causing the persistence in volatility to be low.

With the help of the calibrated LRR models, I investigate the connection between the equity risk premium and the variance risk premium. I show that when data includes the financial crisis years, the return predictability by the variance premium is severely weakened. However, there is evidence to suggest that it is driven by a few outliers and that data up to 2007 may be more appropriate for comparisons. Furthermore, I find that a jump-in- 
volatility model can successfully demonstrate empirically observed predictability, both in the magnitude of the estimated coefficients and the $\mathrm{R}^{2} \mathrm{~s}$ of the regression. In contrast, a jump-ingrowth model generates a statistically significant return predictability with a rather small $\mathrm{R}^{2}$ that suggests small economic significance. This finding stands in contrast to Drechsler and Yaron (2011), who find that the jump-in-growth model creates realistic stock predictability. Two factors may explain the difference. First, Drechsler and Yaron (2011) do not calibrate based on VIX dynamics; second, when regressing excess returns on the variance risk premium, they use "estimated" variance risk premiums for the empirical regressions and use "perfect" variance risk premiums for the model-based regressions.

The LRR models suggest that not only does the variance risk premium predict the equity risk premium, but that the two are also related through jump risks, as investors in equity markets require compensation for taking the jump risks. I use the model to decompose the instantaneous equity risk premium into the diffusion and jump components. ${ }^{5}$ I find that the average proportion of equity premium that is the compensation for taking jump risks is from $35-40 \%$ for the jump-in-growth model and 16-20\% for the jump-in-volatility model. Therefore, the LRR models imply sizable compensation for jump risks in equity investing.

Aside from the jump-diffusion model, I also investigate whether the diffusion-only LRR models can generate significant variance risk premium. Two LRR models are investigated. The first is a one-factor, diffusion-only LRR model similar to Bansal and Yaron (2004). The second is a multi-factor diffusion-only LRR model. Through a systematic calibration, I find both models capable of generating realistic moments in real risk-free rates, price-dividend ratios, and stock returns, as has been suggested by other studies. However, both models generate very small variance premiums compared to the empirical data. This conclusion is in contrast to Bollerslev et al. (2009) and Zhou and Zhu (2009). The different conclusions may be attributed to the difference in model specifications and the calibration approaches.

\footnotetext{
${ }^{5}$ Under the continuous-time framework, only instataneous equity risk premiums can be expressed in a closed form, while the annual equity risk premium can only be evaluated through simulation. However, the average instantaneous equity risk premium turns out to be very close to the long-term simulated annual equity risk premium, making our evaluation relevant.
} 
In particular, Bollerslev et al. (2009) choose a partial equilibrium approach to solve the LRR model and Zhou and Zhu (2009) do not check how their models match volatility dynamics. My evidence suggests that under a strict general equilibrium framework, it is difficult for a diffusion-only LRR model to generate a large variance risk premium.

The main body of this paper is organized as follows: Section 2 outlines the data; Section 3 studies the traditional diffusion-only LRR models; Section 4 studies jump-diffusion LRR models; Section 5 discusses the relation between the variance risk premium and the equity risk premium; Section 6 studies other implications of the LRR models; Section 7 concludes.

\section{Empirical Data}

\subsection{Summary Statistics}

Table 1 reports the summary statistics of data on consumption, dividend, and asset prices. The top panel presents the summary data of annual consumption and dividend growth from 1951 to 2010. Consumption is collected from The Bureau of Economic Analysis (BEA) and the dividend series is constructed based on data from the Center of Research in Security Prices (CRSP) and COMPUSTAT. The cash dividend yield is calculated based on the difference between value-weighted market returns with and without dividends. The total dividend yield, which is used in calibration, is constructed by adding stock repurchases as in Boudoukh et al. (2007). ${ }^{6}$ The aggregate consumption has an average annual growth rate of approximately $2 \%$, a standard deviation of $1 \%$, and a moderate first autocorrelation of 0.38. The two dividend measures have significantly different characteristics. The average growth rate of the repurchase-adjusted dividend is $2.6 \%$, much higher than that of the cash dividend which is $1 \%$. Moreover, the repurchase-adjusted dividend is much more volatile, leptokurtic, and persistent than the cash dividend.

\footnotetext{
${ }^{6}$ Since stock repurchasing data are only available after 1971, we do not adjust dividends for the period before 1971. As shown in Boudoukh et al. (2007), before 1971, payouts to investors were mainly in the form of cash dividends.
} 
The middle panel reports the asset pricing data (except the high-frequency and VIX data) at monthly frequencies over the period from 1951.1 to 2010.7. The nominal risk-free rates are represented by yields on three-month U.S. Treasury bills, which are obtained from the Fama Risk-free Rate Data Set in CRSP. The log price-dividend ratios are the logs of the ratios of the end-of-month S\&P 500 index to the trailing 12 month total dividends. Just like in the top panel, including stock repurchases significantly decreases the growth of price-dividend ratios since 1990 and makes log price-dividend ratios less trendy, as shown in Figure 1.

All the nominal quantities except for the risk-free rates are adjusted to real terms based on the ex post inflation rates, which are constructed based on Survey of Professional Forecasters (SPF) forecasts of the GDP price deflator since 1968 and based on smoothed ex post inflation data before then. SPF forecasts of the GDP price deflator instead of the CPI deflator are used mainly because the survey data of the GDP deflator has a much longer history than that of the CPI deflator (available since 1981). For most of the postwar period, the GDP deflator tracks the consumer price index (CPI) quite closely, as shown in Figure 2.

The middle panel also records summary statistics for stock realized variance and realized volatility. For the period from 1951 to 1989, the realized variance is calculated by summing the daily squared returns over a month. For the period from 1990 to 2010, it is calculated by summing over a month the 5-min intra-day trades of S\&P 500 futures adjusted for overnight price changes. The average realized volatility, which is the square root of the realized variance, is $13.38 \%$ from January 1951 to July 2010. Although the 12-month lag autocorrelation of the realized variance is quite small, the 12-month lag autocorrelation of the realized volatility is 0.28 . The slow decay in volatility autocorrelation is evidence for the long-memory characteristics of stock volatility.

The bottom panel of Table 1 reports the summary statistics for the post-1990 part of the monthly realized variance and realized volatility, the square of the end-of-month VIX volatility index $\left(\mathrm{VIX}^{2}\right)$ and VIX, and the estimated variance risk premiums from 1990 to 2010. VIX data are from the Chicago Board of Trade (CBOE). Variance risk premiums 
are measured by the difference between the expected variance $\left(\mathrm{VIX}^{2}\right)$ under the $\mathbb{Q}$ measure and the expected variance under the $\mathbb{P}$ measure. At the one-month horizon, the former is represented by the VIX ${ }^{2}$. The latter is measured through the HAR-RV (heterogeneousautoregressive realized-volatility) approach adopted by Corsi (2009) and Andersen et al. (2007). This approach involves conducting an in-sample regression of $\log R V_{t}$ on the $\log$ realized variance of past day, week, month, quarter, and half-year, which is

$$
\begin{aligned}
\log R V_{t, t+22}= & \beta_{0}+\beta_{1} \log R V_{t-1, t}+\beta_{2} \log R V_{t-5, t} \\
& +\beta_{3} \log R V_{t-22, t}+\beta_{4} \log R V_{t-132, t}+\epsilon_{t}
\end{aligned}
$$

and then constructing the expected realized variance based on the regression. Studies in Corsi (2009) and Andersen et al. (2007) find this simple and intuitive method to be at least on par with many sophisticated volatility forecasting models, and sometimes even better.

As shown in the bottom panel, both the realized variance risk premium (the difference between $V I X^{2}$ and $R V$ ) and the (expected) variance risk premium are positive on average. ${ }^{7}$ At the same time, the monthly autocorrelations of the VIX decay quite slowly from one month to twelve months, providing evidence that volatility is driven by multiple factors.

\subsection{Variance Risk Premium's Return Predictability: Empirical Findings}

One of the most interesting findings about the variance risk premium is its ability to forecast stock returns in the short run. Both Bollerslev et al. (2009) and Drechsler et al. (2009) find the existence of economically significant return predictability peaking at the quarterly horizon. This paper runs predictive regressions with the HAR-RV measurement of the variance risk premium. It includes two sample periods: January 1990 to December 2007 and January

\footnotetext{
${ }^{7}$ Although the variance risk premium is by definition an ex ante premium, I slightly abuse the notation by calling the difference between the VIX ${ }^{2}$ and the ex post realized variance the "realized variance risk premium".
} 
1990 to July 2010. The regression is in the form of

$$
\sum_{j=1}^{J}\left(r_{m, t+j}-r_{f, t+j-1}\right)=\beta_{0}+\beta_{1} V R P_{t}+\varepsilon_{t}
$$

where $J$ represents the forecasting horizon, $r_{m, t+j}-r_{f, t+j-1}$ represents the excess return at the period $j$, and $V R P_{t}$ represents the variance risk premium at month $t$. Two approaches are used to calculate the regression statistics. The first one is based on the monthly multivariate VAR regressions as in Hodrick (1992). The second one is based on the overlapping OLS regressions with Newey and West (1987) standard errors (use 12 lags).

Table 2 reports the empirical regression results. The main message reflected in this table is that the regression result can be impacted by the VRP estimation period and the regression method. The left panel reports the regression estimates and the VAR-implied $\mathrm{R}^{2}$ values. From 1990 to 2007, the variance risk premium has economically significant predictability on excess equity returns. The predictability is strongest at the horizon of 3 months. For the 1990-2010 period, however, the predictability disappears. The right panel of the table reports OLS regression results and the conclusion is similar: for the period from 1990 to 2007, there exists statistically significant predictability; while for the period from 1990 to 2010, there is none. This result is also consistent with what Bekaert and Engstrom (2009) find.

The relatively short period for the data and the large spike in stock variance makes inference difficult. The insignificant regression result may either be due to the fact that the HAR-RV method gives a biased estimate of the $\mathbb{P}$ measure expected variance during the financial crisis or the relationship between volatility and return is affected by outliers. In an unreported study, I remove two months' observations (September and October of 2008) from the regression data and find the OLS regressions once again significant. Since the September and October of 2008 represent the height of the financial crisis and stock variance experienced unprecedented spikes, these two months' data are potentially outliers 
so that they may distort the regression conclusion. While a more systematic approach for dealing with outliers are needed in the future, for now, I take the result based on the period from 1990 to 2007 as the benchmark empirical result for all LRR models to compare.

\section{Can One- or Two-Factor LRR Models Generate Vari- ance Risk Premium?}

\subsection{Model Setup}

\section{Preferences}

Following the standard LRR literature, I assume that investors have Epstein-Zin-Weil preferences. Under the continuous-time framework, the recursive utility function is

$$
U(t)=\left\{\left(1-e^{-(\ln \delta) d t}\right) C_{t}^{1-\frac{1}{\psi}}+\left(e^{-(\ln \delta) d t}\right) E_{t}\left(U(t+d t)^{1-\gamma}\right)^{\frac{1-\frac{1}{\psi}}{1-\gamma}}\right\}^{\frac{1}{1-1 / \psi}},
$$

where $\ln \delta$ is the compound discount rate, $\gamma$ is the degree of risk aversion, and $\psi$ represents the elasticity of intertemporal substitution (EIS). The continuous-time dynamics of the log of the Intertemporal Marginal Rate of Substitution(IMRS) $m_{t}$ is

$$
d m_{t}=\theta \ln \delta d t-\frac{\theta}{\psi} d c_{t}-(1-\theta) r_{c, t}
$$

where $\theta=(1-\gamma) /(1-1 / \psi), d c_{t}$ is the growth rate of $\log$ consumption. $r_{c, t}=\ln \frac{P_{t+d t}^{c o n}+C_{t+d t}}{P_{t}^{c o n}}$ represents the log of the instantaneous return of an asset which is a claim on the consumption stream and $P_{t}^{c o n}$ is the price of the consumption-based asset. ${ }^{8}$

Under the standard Campbell-Shiller log-linearization approximation, both return on consumption-claim assets $r_{c, t}$ and dividend-claim asset $r_{d, t}$ are approximated as linear func-

\footnotetext{
${ }^{8}$ Analogously, the log of the instantaneous return of an asset that is a claim on the dividend stream is defined as $r_{d, t}$, where $r_{d, t}=\ln \frac{P_{t+d t}+D_{t+d t}}{P_{t}}$ represents the market return on dividend-claim assets.
} 
tions of the $\log$ wealth-consumption ratio $v_{t}^{c}$ and the $\log$ price-dividend ratio $v_{t}^{d}$, i.e.

$$
\begin{aligned}
& r_{c, t}=k_{0} d t+k_{1} \Delta v_{t}^{c}-\left(1-k_{1}\right) v_{t}^{c} d t+d \log C_{t} \\
& r_{d, t}=k_{0 d} d t+k_{1 d} \Delta v_{t}^{d}-\left(1-k_{1 d}\right) v_{t}^{d} d t+d \log D_{t}
\end{aligned}
$$

where $\Delta v_{t}^{c}$ and $\Delta v_{t}^{d}$ represent the instantaneous changes of the two log ratios. $k_{1}, k_{0}, k_{1 d}$, and $k_{0 d}$ are constants determined by the unconditional means of $v_{t}^{c}$ and $v_{t}^{d} ; v_{t}^{c}=\log \left(P_{t}^{c o n} / C_{t}\right)$ rep-

resents the $\log$ wealth-consumption ratio; $v_{t}^{d}=\log \left(P_{t} / D_{t}\right)$ represents the log price-dividend ratio. The details of the derivations can be found in Eraker and Shaliastovich (2008) and Appendix A.

\section{Economic Fundamentals}

I follow the standard LRR literature to assume that investors make decisions under a continuous-time, real endowment economy where consumption and dividend are correlated but separate processes. The growth dynamics of $\log C_{t}$ and $\log D_{t}$ can be written as

$$
\begin{aligned}
d \log C_{t} & =\left(\mu_{C}+x_{t}-\frac{1}{2} V_{t}^{s}\right) d t+\sqrt{V_{t}^{s}} d W_{c, t} \\
d \log D_{t} & =\left(\mu_{D}+\phi_{D} x_{t}-\frac{1}{2} \varphi_{d}^{2} V_{t}^{s}\right) d t+\varphi_{d} \sqrt{V_{t}^{s}} d W_{d, t} \\
d W_{c, t}, d W_{d, t} & \sim N(0,1), \operatorname{corr}\left(d W_{c, t}, d W_{d, t}\right)=\rho_{d c}
\end{aligned}
$$

where $\mu_{C}$ and $\mu_{D}$ are the log of the average consumption growth rates and the log of the average dividend growth rates, $\frac{1}{2} V_{t}^{s}$ and $\frac{1}{2} \varphi_{d}^{2} V_{t}^{s}$ are adjustment terms for Jensen's inequality where $V_{t}^{s}$ is the volatility factor; $x_{t}$ represents the long-run consumption growth; $\phi_{D}$ characterizes the sensitivity of dividend growth on $x_{t}$; the scaling factor $\varphi_{d}$ captures the high leverage of the dividend growth relative to consumption; $d W_{c, t}$ and $d W_{d, t}$ are Brownian motions with a correlation of $\rho_{d c}$.

In a generalized two-factor LRR model, $x_{t}, V_{t}^{f}$ and $V_{t}^{s}$ are state variables with stochastic 
volatility dynamics

$$
\begin{aligned}
d x_{t} & =-\kappa_{x} x_{t} d t+\varphi_{e} \sqrt{V_{t}^{f}} d W_{x, t} \\
d V_{t}^{f} & =\kappa_{v}^{f}\left(V_{t}^{s}-V_{t}^{f}\right) d t+\sigma_{w}^{f} \sqrt{V_{t}^{f}} d W_{v, t}^{f} \\
d V_{t}^{s} & =\kappa_{v}^{s}\left(\bar{V}_{s}-V_{t}^{s}\right) d t+\sigma_{w}^{s} \sqrt{V_{t}^{s}} d W_{v, t}^{s} \\
d W_{x, t}, d W_{v, t}^{f}, d W_{v, t}^{s} & \sim N(0,1), \operatorname{corr}\left(d W_{x, t}, d W_{v, t}^{f}\right)=\rho_{x f} .
\end{aligned}
$$

Here $\kappa_{x}, \kappa_{v}^{f}, \kappa_{v}^{s}, \sigma_{w}^{f}$ and $\sigma_{w}^{s}$ are parameters that characterize the stochastic volatility dynamics. Since this model has two volatility factors, I label it the SV2F model. When $V_{t}^{f}$ and $V_{t}^{s}$ degenerate to the same factor, the model becomes a one-factor model and quite similar to the original Bansal and Yaron (2004) model except for the square-root diffusion term. I refer to the degenerate model as the SV1F model.

The specifications above fall into the generalized affine form that was discussed by Eraker et al.(2008). The state variable $Y_{t}$ is $\left[x_{t}, V_{t}^{f}, V_{t}^{s}\right]$ for the SV2F model and $\left[x_{t}, V_{t}^{s}\right]$ for the $\mathrm{SV} 1 \mathrm{~F}$ model and can be expressed in vector form

$$
\begin{aligned}
d Y_{t}= & \left(M+K^{\prime} Y_{t}\right) d t+\Sigma\left(Y_{t}\right) d W_{t} \\
d Y_{t}= & \left(M^{Q}+K^{Q} Y_{t}\right) d t+\Sigma\left(Y_{t}\right) d W_{t}^{Q}, \\
& \Sigma\left(Y_{t}\right) \times \Sigma\left(Y_{t}\right)^{\prime}=h+\sum_{i} H_{i} Y_{t}
\end{aligned}
$$

where $M \in \mathbb{R}^{n \times 1}, K \in \mathbb{R}^{n \times n}$, and $(h, H) \in \mathbb{R}^{n \times n} \times \mathbb{R}^{n \times n \times n}$. The details of the transformation between the $\mathbb{P}$ and $\mathbb{Q}$ measures are shown in Appendix A.

\section{Equilibrium Solution}

I obtain the equilibrium model solution by solving the Euler equation

$$
E_{t}\left[\exp \left(m_{t}+r_{i, t}\right)\right]=1, i \in\{c, d\}
$$


where $m_{t}$ is the log pricing kernel and $r_{c, t}$ and $r_{d, t}$ are the instantaneous returns of assets with claims on consumption and dividend respectively from time $t$ to $t+d t$.

As shown in Appendix A, I use the standard guess-and-verify procedure to solve the Euler equation. The solutions of the $\log$ wealth-consumption ratio $v_{t}^{c}$, the $\log$ price-dividend ratio $v_{t}^{d}$, and the risk-free rates $r_{t}$ are affine functions of state variables: ${ }^{9}$

$$
\begin{aligned}
& v_{t}^{c}=A+B^{\prime} Y_{t} \\
& v_{t}^{d}=A_{d}+B_{d}^{\prime} Y_{t} \\
& r_{t}=\Phi_{0}+\Phi_{1}^{\prime} Y_{t}
\end{aligned}
$$

where $A, B, A_{d}, B_{d}, \Phi_{0}, \Phi_{1}$ are functions of state variables and preference parameters. $A, A_{d}$ and $\Phi_{0}$ are scalars and $B, B_{d}$, and $\Phi_{1}$ are $n \times 1$ vectors.

The quardratic variation of return process $Q V_{t, t+1}$ can be expressed as

$$
Q V_{t, t+1} \equiv \int_{\tau=t}^{t+1} d[\log S, \log S]_{\tau}
$$

where the square brackets represent the standard quardratic variation process. Using the continuous-version approach of Eraker (2008), I can also deduce the model implied riskneutralized expected variance $E^{Q}\left[Q V_{t, t+1}\right]$ and expected realized variance $E^{P}\left[Q V_{t, t+1}\right]$ with the calculation detailed in Appendix A. The model-implied variance risk premium $(V R P)$ is simply calculated as

$$
V R P=E^{Q}\left[Q V_{t, t+1}\right]-E^{P}\left[Q V_{t, t+1}\right]
$$

\footnotetext{
${ }^{9}$ The affine structure of the solution process is valid under the Campbell-Shiller log-linearization approximation. As shown by Bansal et al. (2007b), as long as the EIS is not significantly higher than 2 (which is satisfied in our study), this log-linear approximation yields a result quite close to the more accurate numerical solution to the Euler equation.
} 


\subsection{Calibration and Moment Match}

I calibrate the model based on various asset pricing moments of interest. These moments include first and second moments in equity price-dividend ratios, short interest rates, stock realized volatility and VIX. They also include the lag 1 autocovariance of risk-free rates and the lag 1,6 , and 12 autocovariances of VIX. ${ }^{10}$ The calibration strategy is based on the SMM (Simulated Methods of Moments), which helps to systematically find the best parameters to fit the overall moments, the details of implementing the SMM is in Appendix B.

My calibration strategy relies on exploring the conditional information from option markets, an approach adopted in Shaliastovich (2009) and Eraker (2008). Shaliastovich (2009) uses cross-sectional options data while Eraker (2008) considers index-like VIX data constructed from a basket of options. Cross-sectional options data certainly contain rich information on the investors' attitudes towards market risk, yet individual options pricing, especially in the in-the-money (ITM) or deep out-of-the-money (OTM) ranges, can be subject to large biases due to possible model-pricing errors. I therefore follow Eraker (2008) to calibrate the models based on VIX data that are constructed in a "model-free" way.

For each calibrated model, I split the parameters into two groups. The parameters in the first group are preset at values consistent with most of the previous LRR studies and are presented in Panel A of Table 3. All the other parameters are obtained by the SMM. Among these parameters, the loading factor of the dividend growth on the volatility factor $\varphi_{d}$ is chosen among discrete values of $[5,6.5,8,9.5,11]$. For each candidate value $\varphi_{d}$, I optimize the objective function and choose a $\varphi_{d}$ that enables the model to achieve the best fit. I also start from various initial values of the calibrated parameters to make sure that the parameter set achieves an optimal fit among a large set of possible parameters.

The results of calibration are presented in Table 3. For the SV1F model, the calibrated parameters are similar to Bansal et al. (2004). For the SV2F model, the mean-reverting

\footnotetext{
${ }^{10} \mathrm{I}$ do not include the autocovariance in realized stock volatility as this will allow the model to be compared with previous studies more easily. However, I do investigate how the calibrated models fit the data on that dimension.
} 
parameter is much higher for $V_{t}^{f}$ than for $V_{t}^{s}$, while the volatility of $V_{t}^{f}$ is much higher than that of $V_{t}^{s}$. Overall, the SV1F and SV2F models fit the data poorly with large J-statistics but the SV2F model achieves a slightly better overall fit.

Table 4 reports moment matches between simulated data from calibrated models and empirical data. The model-implied moments are medians of 1000 simulations with each simulation spanning a period of 60 years. Long-time simulation moments are close to these median values jointly (not reported here). In the data column, the numbers in the brackets are the adjusted averages taking into account the shorter length of VIX data. In the model column, the numbers in brackets correspond to the $5 \%$ and $95 \%$ quantiles of the simulated moments.

As shown in the table, the two models achieve decent fits to the first and second moments of interest rates, price-dividend ratios, and historical stock volatility. However, the average model-implied VIX is $13.6 \%$ for the SV1F model and $12.6 \%$ for the SV2F model, significantly lower than the sample average VIX of $20.4 \%$; even the adjustment taking into account the missing VIX values before 1990 cannot explain such large discrepancies. Consequently, both two models generate variance risk premiums that are one magnitude smaller than the sample average. This result shows that even a multi-factor model cannot generate a significant variance risk premium.

This result also runs contrary to Bollerslev et al. (2009) and Zhou and Zhu (2009). Aside from model specifications, the difference may also be due to the different calibration approaches. Particularly, Bollerslev et al. (2009) choose a partial equilibrium strategy to solve the LRR model by setting the wealth return's loading on the wealth-consumption ratio $\left(\kappa_{1}\right)$ to be a constant value of 0.9 , while in principle, this parameter should be solved recursively ${ }^{11}$. On the other hand, Zhou and Zhu (2009) propose a quite general two-factor model which generates a significant variance risk premium but at the cost of generating much smaller than empirically observed price-dividend ratios. ${ }^{12}$ Both Bollerslev and Zhou

\footnotetext{
${ }^{11}$ I find that for all the models discussed in this paper, the $\kappa_{1} \mathrm{~s}$ are about 0.999 .

${ }^{12}$ They also do not check the model's implication on the persistence in realized or risk-neutral volatility.
} 
and Zhu (2009) do not provide evidence on how their models match volatility dynamics, making direct comparison between theirs and mine more difficult. However, the evidence in this paper suggests that it is difficult for a two-factor LRR model to simultaneously generate large variance risk premium and realistic volatility dynamics. Finally, the modelimplied autocorrelation in VIX generated by the SV1F model decays quickly to 0 as the interval increases to 12 months; in contrast, the SV2F model demonstrates a non-trivial autocorrelation even at the 12-month interval. This is presumably why the SV2F model achieves a better overall fit to the data than the SV1F model.

\section{Calibrating One- or Two- Factor LRR Jump-Diffusion Models}

\subsection{Model Setup}

Given the incapabilities of the SV1F and SV2F models to explain the large variance risk premium. I add jump processes to the state variables to investigate how jump-diffusion models can make the difference. I focus on three groups of models: the one-factor jump-diffusion model (SVJ1F_G(V)), the two-factor jump-diffusion model with short-run consumption and long-run consumption sharing the same volatility factor (SVJ2F_G(V)_A), and the twofactor jump-diffusion model with the short-run consumption having persistent volatility and the long-run consumption growth having non-persistent volatility (SVJ2F_G(V)_B).

The economic fundamentals for all three sets of LRR models can be written in a general 
form as

$$
\begin{aligned}
d \log C_{t}= & \left(\mu_{C}+x_{t}-\frac{1}{2}\left(\delta_{c} V_{t}^{f}+\left(1-\delta_{c}\right) V_{t}^{s}\right) d t\right. \\
& +\sqrt{\delta_{c} V_{t}^{f}+\left(1-\delta_{c}\right) V_{t}^{s}} d W_{c, t}, \\
d \log D_{t}= & \left(\mu_{D}+\phi_{D} x_{t}-\frac{1}{2} \varphi_{d}^{2}\left(\delta_{c} V_{t}^{f}+\right.\right. \\
& \left.\left.\left(1-\delta_{c}\right) V_{t}^{s}\right)\right) d t+\varphi_{d} \sqrt{\delta_{c} V_{t}^{f}+\left(1-\delta_{c}\right) V_{t}^{s}} d W_{d, t} \\
d W_{c, t}, d W_{d, t} \sim & N(0,1), \operatorname{corr}\left(d W_{c, t}, d W_{d, t}\right)=\rho_{d c} .
\end{aligned}
$$

and the state variable dynamics for all three groups of model are

$$
\begin{aligned}
d x_{t}= & -\kappa_{x} x_{t} d t+\varphi_{e} \sqrt{V_{t}^{f}} d W_{x, t}+\xi_{x} d N_{x}, \\
d V_{t}^{f}= & {\left[\kappa_{v}^{f}\left(V_{t}^{s}-V_{t}^{f}\right)\right] d t+\sigma_{w}^{f} \sqrt{V_{t}^{f}} d W_{v, t}^{f}+} \\
& \xi_{V f} d N_{V f}-E\left(\xi_{V f}\right) E\left(d N_{V f}\right), \\
d V_{t}^{s}= & \kappa_{v}^{s}\left(\bar{V}_{s}-V_{t}^{s}\right) d t+\sigma_{w}^{s} \sqrt{V_{t}^{s}} d W_{v, t}^{s}, \\
d W_{x, t}, d W_{v, t}^{f}, d W_{v, t}^{s} \sim & N(0,1), \operatorname{corr}\left(d W_{x, t}, d W_{v, t}^{f}\right)=\rho_{x f} .
\end{aligned}
$$

Here the parameters in the diffusion part have the same meaning as in the SV2F model except for the jump term in $x_{t}, \xi_{x} d N_{x}$, and the jump term in $V_{t}^{f}, \xi_{V f} d N_{V f}-E\left(\xi_{V f}\right) E\left(d N_{V f}\right)$.

For the first set of models, there is only one volatility factor, so $V_{t}^{f}$ and $V_{t}^{s}$ degenerate into one factor, which means instead of reverting to time-varying $V_{t}^{s}, V_{t}^{f}$ reverts to a constant mean. Additionally, I set $\delta_{c}=1$ (it makes no difference when there is only one volatility factor). I assume that there are either jumps in the long-run growth rate $x_{t}$, which means the jump intensity in $V_{t}^{f}$ is zero; or jumps in the volatility factor which means the jump intensity in $x_{t}$ is zero. This set of models is referred to as the SVJ1F_G(V) model. For the second set of models, I set $\delta_{c}=1$ and keep the volatility factors $V_{t}^{f}$ and $V_{t}^{s}$. This set of models is referred to as the $\mathrm{SVJ}_{2} \mathrm{~F}_{-} \mathrm{G}(\mathrm{V})_{-} \mathrm{A}$ model. This setup is similar to the specification in Drechsler and Yaron (2011). For the third set of models, I set $\delta_{c}=0$, and the state variable 
dynamics as in Eq. 15, this group is referred to as the SVJ2F_G(V)_B model and the model can be interpreted as a reduced-form representation of the confidence-based LRR model proposed by Bansal and Shaliastovich (2009).

For all three sets of models, I assume that jumps are Poisson processes with intensity being affine functions of the sole or the short-run volatility risk factor $V_{t}^{f}$, i.e.

$$
\begin{aligned}
\operatorname{Prob}\left(d N_{x}\right. & \left.=1 \mid I_{t}\right)=l_{X V} V_{t}^{f} d t \\
\operatorname{Prob}\left(d N_{V f}\right. & \left.=1 \mid I_{t}\right)=l_{V} V_{t}^{f} d t
\end{aligned}
$$

where $l_{X V}$ and $l_{V}$ are intensity coefficients. This reflects the state-dependent feature of the jump processes: a high-volatility state implies a high probability of a sudden change in the expected long-run consumption growth rates or volatility.

Following Drechsler and Yaron (2011), I assume the jump size of $x_{t}$ and $V_{t}^{f}$ to be a left-skewed compensated Gamma distribution and a right-skewed Gamma distribution respectively, i.e.

$$
\begin{aligned}
& \xi_{x} \sim-\Gamma\left(\gamma_{x}, \frac{\mu_{x}}{\gamma_{x}}\right)+\mu_{x} \\
& \xi_{V} \sim \Gamma\left(\gamma_{V}, \frac{\mu_{V}}{\gamma_{V}}\right) .
\end{aligned}
$$

where $\gamma_{x}$ and $\gamma_{V}$ are shape parameters and are preset to the standard value of 1 ; while $\mu_{x}$ and $\mu_{V}$ are scale parameters that characterize the magnitude of the jumps and are determined in optimization. The distribution of $x_{t}$ implies that $x_{t}$ has many small positive jumps and a few large negative jumps so that the overall average jump size is zero. The distribution of $V_{t}^{(f)}$ implies that there are relatively infrequent large spikes in market volatility. 


\subsection{Calibration and Moment Match}

As detailed in Appendix A, adding jumps to the model does not change the affine characteristics of the model and the calculation formula for the expected variance and the calibration procedure are the same as in the diffusion-only case. The calibration results are reported in Table 5. The first panel displays preset parameters which are mostly the same as in the SV1F and SV2F models except for the extra jump intensity and shape parameters. The shape parameters are all set to 1 . The growth jump intensity parameter $l_{X V}$ is set to 4000 , and the volatility jump parameter $l_{V}$ is set to 500 . With a long-term mean $V_{t}^{(f)}$ of $1.5 \times 10^{-5}$; the jump frequency of $x_{t}$ corresponds to roughly 0.72 jump/year and the jump frequency of $V_{t}^{(f)}$ corresponds to 0.09 jump/year. The $l_{X V}$ parameter is well aligned with previous calibrated parameters in Drechsler and Yaron (2011), but unlike Drechsler and Yaron (2011) who set $l_{V}=l_{X V}$, I set $l_{V}$ to a much lower value which is more aligned with Eraker (2008).

The second panel in Table 5 displays parameters that are found through the SMM. As can be seen, including jump process significantly improves fitting quality across all models. Generally, a multi-factor jump-diffusion model performs better than a single-factor jumpdiffusion model, which means including a second volatility factor also improves model fit. Both the risk aversion parameter and the EIS parameter for each model are similar to Drechsler and Yaron (2011) and other studies. For a single-factor model, the monthly meanreverting rate of volatility factor $\kappa_{v}$ is 0.2 , much higher than previously reported in other LRR studies $(\sim 0.1)$. This is the result of calibrating the model based on monthly autocovariance in VIX. For multi-factor models, the mean-reverting rate for the non-persistent volatility factor $V_{t}^{f}$ ranges from 0.24 to 0.51 , representing half lives of 1 to 2.5 months, while the meanreverting rate for the persistent volatility factor $V_{t}^{s}$ ranges from 0.010 to 0.017 , representing half lives of 40 to 70 months. ${ }^{13}$ The existence of such a persistent volatility factor has been pointed out by Egloff et al. (2010), Chacko and Viceira (2003), and others.

\footnotetext{
${ }^{13}$ The half-life $\mathrm{H}$ is defined as the number of months for the autocorrelation of the process to decay to half of its monthly autocorrelation level, $H=\ln (0.5) / \ln \left(1-\kappa_{v}\right)$.
} 
The overidentification parameter (OID) summarizes the overall fits between the calibrated models and the moments used for calibration. When comparing models with the same moments used for calibration, jump-in-growth models SVJ1F_G and SVJ2F_G_A underperform their jump-in-volatility counterparts, but the SVJ2F_G_B model outperforms the SVJ2F_V_B model and achieves the best in-sample fit across all models. However, when testing the goodness-of-fit of all original calibrated models against an expanded set of moments that also include the autocovariance moments in realized volatility, all jump-in-growth models display much quicker drops in fitting quality. In contrast, jump-in-volatility models' overall fitting quality only worsen slightly. For example, the OID test value for the SVJ2F_V_B model increases from 79.1 to 112.2 when autocovariance moments in realized stock volatility are included; in contrast, the OID test value for the SVJ2F_G_B model increases from 44.6 to 278.4.

Table 6 reports the moment match for the jump-diffusion models. As in Table 4, the value reported is the median of 1000 simulations, with each simulation spanning 60 years. The brackets in the data columns indicate the adjusted means taking into account the shorter length of VIX data and the brackets in the model columns indicate $5 \%$ and $95 \%$ quantiles in the simulated moments. As shown in Panel A, all jump models display remarkable in-sample fits for the first and second moments of risk free rates, price-dividend ratios, and historical realized volatility. ${ }^{14}$ They also imply an annual equity risk premium of 5 to 6 percent. The biggest improvement of the jump-diffusion LRR models over the diffusion-only LRR models is that they all display significant positive variance risk premiums that are comparable to the adjusted empirical variance risk premium. This is consistent with the argument in Drechsler and Yaron (2011) that investors' fear of large jumps in either asset prices or volatility of asset prices makes them willing to pay a premium to hedge the time-varying stock volatility.

\footnotetext{
${ }^{14}$ One exception is the volatility of risk free rates. All models imply a value of about $1 \%$ annually, while the empirical estimate is $2 \%$. However, it is well-known that estimating the volatility of real risk-free rates is difficult. In fact, using ex post inflation rates to adjust nominal rates would give an annual volatility of $4 \%$ that is much higher than implied by most LRR models. By using smoothed or survey-based estimates of expected inflation rates, the discrepancy between models and data has already been significantly reduced.
} 
Within the same type of LRR models (the same setup except for the jump channel), a jumps-in-growth model generally generates a higher average variance risk premium than its jumps-in-volatility counterparts.

Volatility dynamics are directly related to the dynamics of the underlying stock volatility factors, which in turn affect the risk-return trade-off, return predictability, and valuations for long-term options and variance swap contracts. Therefore, it is important to check whether an equilibrium asset pricing model can generate realistic volatility dynamics under both riskneutral and historical measures. Panel B of Table 6 reports moment matches in volatility dynamics. When comparing the model-generated VIX autocorrelation moments to the data, I find that it is not whether the model contains one or two volatility factors that determines the fitting quality; instead, it is the jump channel that matters, particularly, jump-in-growth models generate low median values for 6- and 12-month VIX autocorrelations. Except for the SVJ2F_G_B model, the sample value is outside the $90 \%$ confidence interval implied by the jump-diffusion models. In contrast, even a single-factor jump-in-volatility model generates good fits in the 6- and 12-month VIX autocorrelations. I find that the VIX autocorrelations implied by jump-in-growth models are vulnerable to small-sample effect. Fo example, a 10,000 month simulation of the SVJ2F_G_B model generates a 6-month VIX autocorrelation of 0.43 and a 12-month VIX autocorrelation of 0.37 (not reported in the table); however, the median values of 1000 simulations of 720 months for these two autocorrelations are only 0.25 and 0.19 , respectively.

As for the realized volatility dynamics, jump-in-volatility models also perform better than jump-in-growth models in terms of matching the data. For each of the SVJ1F_G and SVJ2F_G_A models, the 1-month autocorrelations in stock volatility match the data reasonably well, however, the 6-month and 12-month autocorrelations are apparently smaller than the data suggest. For the SVJ2F_G_B model, the autocorrelations in realized volatility at all horizons are smaller than the sample average. In contrast, the multifactor jump-involatility models match the realized volatility persistence fairly well, consistent with the 
goodness-of-fit tests reported in Table 6 .

To interpret why jump-in-growth models performs more poorly when matching volatility dynamics than jump-in-volatility models? One notice that a jump-in-volatility model implies that when there is a large positive volatility jump, there is also a large price jump. Therefore, the realized volatility is high. On the other hand, a positive jump in volatility impact future volatility factor through the AR(1) process, meaning that future VIX and realized volatility would also be high. The volatility clustering effect is hence maintained well in jump-in-volatility models. In contrast, it is difficult for a jump-in-growth model to generate the volatility clustering effect. Although a negative jump in the long-run growth cause a contemporaneous surge in realized volatility, the surge is not followed by a surge in future volatility because the volatility factors are unchanged. Therefore, one would see stock volatility quickly revert to normal values after the crisis period and the average correlation in volatility is low. ${ }^{15}$

Finally, I check whether the calibrated models can describe the empirical time series of the VIX ${ }^{2}$. I assume that risk-free rates, price-dividend ratios, and physical expected variance are all observed without errors. Using the fact that within the LRR model, these variables are all affine functions of the state variables, I extract the latent state variables and obtain the model-implied VIX ${ }^{2}$. For the single-factor LRR models, I use risk-free rates and physical expected variance to extract $x_{t}$ and $V_{t}^{f}$; for the multifactor LRR models I use risk-free rates, price-dividend ratios, and physical expected variance to extract $x_{t}, V_{t}^{f}$, and $V_{t}^{s}$. As shown in Figure 3, all jump-diffusion LRR models generate decent fits in the time series of the VIX ${ }^{2}$. Several periods of VIX spikes, including the Asian Crisis and the months when Lehman Brothers bankrupted, are well captured. The only period that the model-implied VIX ${ }^{2}$ being significantly smaller than the observed VIX ${ }^{2}$ is during the months of Russian

\footnotetext{
${ }^{15}$ One would argue for a LRR model that has joint jumps in long-run growth and volatility, a setup similar to Benzoni et al. (2010), so that both variance risk premium and volatility dynamics can be matched well. Given that the calibrated jump intensity for growth is different from the jump intensity for volatility, establishing such models might be non-trivial. However, it is certainly possible to establish a LRR model that incorporate both jumps in long-run growth and jumps in volatility where jump processes have different jump intensities. Establishing such models is beyond the scope of this paper.
} 
debt default and the ensuing LTCM collapse. This is a nontrivial achievement for the LRR models, given that $\mathrm{VIX}^{2}$ is not directly used in extracting the latent state variables. It provides evidence that the jump-diffusion LRR models are capable of not only describing the average moments but the time-series dynamics of variance swap rates as well.

To summarize, incorporating jumps in a LRR model is crucial to generate realistic variance risk premiums and to explain the equity premium puzzle, the low risk-free rate puzzle, and the high volatility puzzle. The jump-in-growth models are generally more effective at generating large variance risk premiums than the jump-in-volatility models are. However, the cost of assuming jumps in long-run consumption growth is reduced persistence in realized volatility and smaller long-run autocorrelation in the risk-neutral volatility represented by VIX. ${ }^{16}$ All jump LRR models do a decent job of fitting the time-series of the VIX ${ }^{2}$ from 1990 to 2010 .

\subsection{Robustness Check}

- Discount factor and dividend dynamics

In the calibration, I set the discount factor at 0.999 and choose the dividend dynamics parameters close to Bansal et al. (2007). In this study, I have tried four different subjective discount factors $(\delta=0.999,0.9985,0.998,0.997)$ and find that only the discount factor of 0.999 allows the model to fit interest rates and price-dividend ratios simultaneously well.

As for the dividend dynamics parameters, I have tested several values of $\phi_{d}$, the dividend growth's loading factor on the long run risk factor $x_{t}$. My experiment suggests that at least within the range of 2.5 to 3.5 , similar sample moments can be achieved by small adjustments

\footnotetext{
${ }^{16}$ Since I wish to focus on volatility dynamics, I do not report the comparison of the higher moments in realized volatility and VIX. Jump-in-volatility models tend to generate higher skewness and kurtosis of realized volatility and VIX than the empirical values, while jump-in-growth models generate a much closer fit. There are two reasons I do not consider comparing these high moments. First, including high moments obscures the focus on volatility dynamics. Second, it is quite difficult to estimate the unconditional skewness and kurtosis for a short sample period. Third, the main focus of this paper is not finding an "optimal" model but an investigatigation of how volatility dynamics can help distinguish different jump channels. A systematic study that not only considers volatility dynamics and high moments in volatility is for future research.
} 
of other parameters; but when $\phi_{d}$ is out of this range, the search for a better fit is increasingly difficult. I also test how changing the coefficient $\rho_{d c}$ would impact the model results. I choose a typical value of 0.4 , but varying it from 0.2 to 0.6 does not materially impact the quality of the model fit, as other parameters can be adjusted accordingly.

- Leverage-effect coefficient

Across the models, I restrict the shock correlation coefficients $\rho_{x f}$ to -0.8 . I find that this coefficient has little effect on monthly aggregate asset moments; however, setting $\rho_{x f}$ to -0.8 can significantly improve the model's description of daily dynamics dependence between stock returns and the VIX index.

- Jump intensity parameter

I also test whether the calibrated jump parameters will affect the result of estimation. In jump-in-growth models, the parameter $l_{X V}$ is set to 4000. In jump-in-volatility models, the coefficient of $l_{V}$ is set to 500. I preset the jump intensity parameters because it is extremely hard to identify jump intensity and jump size jointly. In fact, the experiments suggest that if jump intensity is not varied much, the impact on sample moments can be largely offset by adjusting jump size parameters.

\section{Variance Risk Premium and Equity Risk Premium}

\subsection{Variance Risk Premium's Predictability of Stock Returns}

Table 7 and Table 8 report model-implied predictability of equity premium by the variance risk premium. Table 7 reports statistics based on the VAR regression method of Hodrick (1992). Table 8 reports statistics based on OLS regression. These two tables show that jump-

in-volatility LRR models can replicate the predictability of stock returns by the variance risk premium when expected physical variance is measured by the HAR-RV method. 
The top panel in each table reports the regression results when the expected realized variance is constructed by the "true" volatility state variable across all models. The second panel in each table reports the regression results when the expected realized variance is estimated by applying the HAR-RV method to the simulated data. Comparing these two panels in each table, it is apparent that the predictive power of the HAR-RV-based variance risk premium is much smaller than that of the "true" variance risk premium. For example, for the SVJ2F_V_B model, the highest $\mathrm{R}^{2}$ of return regressions on "true" variance premiums is 0.05 , while the highest $\mathrm{R}^{2}$ of return regressions on estimated variance risk premiums is only 0.02. For jump-in-growth models, the changes in $R^{2} \mathrm{~s}$ are even more significant. The comparison suggests that there is a significant difference between "true" and noisy measures of the variance premium. Since using the "true" variance premium's predicting power in the model to match the "estimated" variance premium's predicting power in the data can potentially overstate the model's ability to account for variance risk premium's return predictability, I focus on the second panel when comparing models against the empirical data.

As shown in Table 7, when the expected variance is estimated by the HAR-RV method and VAR regressions are applied, jump-in-volatility models generate a close match in return predictability by the variance risk premium while the maximum $\mathrm{R}^{2}$ generated in jump-ingrowth models is less than 0.005 . The trends of the $\mathrm{R}^{2} s$ for different forecasting horizons are different too. For each of the two multifactor jump-in-volatility models (SVJ2F _ V_A, SVJ2F_V_B), the $\mathrm{R}^{2}$ peaks at the horizon of 3 months and then gradually decreases. For each of the two multifactor jump-in-growth models (SVJ2F_G_A, SVJ2F_G_B), the R ${ }^{2}$ peaks at the 1-month horizon and then steadily decreases. The coefficients of regression in the jump-in-volatility models also match the coefficients of empirical regressions fairly well.

When OLS regressions are applied, as shown in Table 8 , the $\mathrm{R}^{2} \mathrm{~s}$ are much higher than those in Table 7. The SVJ2F_V_B model generates the closest match in the $\mathrm{R}^{2}$ values, peaking at the 6-month horizon. The regression estimate, however, monotonically increases as the regression horizon increases, which is different with what the data suggest. This 
suggests that the $\mathrm{SVJ}_{2} \mathrm{~F}_{-} \mathrm{V}_{-} \mathrm{B}$ model are able to capture a significant part but not all of the return predictability by the variance risk premium.

\subsection{Unconditional Decomposition of Equity Risk Premium}

Table 9 reports the results for decomposing the instantaneous expected equity risk premium into different parts that are attributed to different risk resources. The second row reports the annualized unconditional mean of the equity risk premiums for all models. The third to sixth rows record the premiums attributed to shocks in short-run consumption growth, shocks in long-run consumption growth, shocks in the short-run volatility factor, and shocks in the long-run volatility factor. The seventh and eighth rows record the equity premiums contributed by jump risks in the long-run component and the volatility factor respectively.

For pure diffusion models such as the SV1F and SV2F models, diffusion risks associated with the long-run risk factor constitute most of the equity risk premium commanded by investors; in both models the number is close to or even more than $90 \%$. When jumps are included, the risk premium attributed to the diffusion in the long-run risk factor $x_{t}$ is significantly reduced. On the other hand, investors command non-trivial proportion of equity premiums to compensate for risks in jumps: for jump-in-volatility models, jump risks contribute $16 \%$ to $21 \%$ of the total unconditional equity risk premium; while in jump-ingrowth models, the percentage varies from $35 \%$ to $41 \%$.

As almost all of the variance risk premium is due to the jumps, this indirectly suggests that variance risk premiums are closely associated with equity premiums. My result is consistent with what Bollerslev and Todorov (2011) find, but the magnitude is much smaller. Using non-parametric methods, Bollerslev and Todorov (2011) find that the risk aversion associated with the tail events not only generates a large variance risk premium, but also constitutes more than $60 \%$ of the equity risk premium. My result implies that most of the premium is still generated by the risk in long-run consumption growth. 


\section{Other Implications of the LRR Model}

\subsection{Moments in Consumption and Dividend}

Although I do not directly include the data regarding consumption and dividend growth in the calibration, it is interesting to compare the implied consumption and dividend of the LRR models and the annualized data. Table 10 reports the comparison results.

For the annual consumption, all models match the means of the annual consumption growth very well. Yet they all generate a slightly higher-than-sample consumption volatility. The models also imply that the consumption growth is normally distributed. The median values of skewness are all very small and the median values of the kurtosis are close to 3 , in contrast to the negative sample skewness of -0.59 and the high kurtosis of 3.47 observed in the post-war data. However, the sample values are well within the $90 \%$ confidence interval implied by all models, as the unconditional skew and kurtosis are hard to estimate robustly. All models suggest a slightly higher first-order autocorrelation in the consumption process than the empirical value of 0.38 . For all models (except for the SVJ2F_G_B model), the empirical value is well within the confidence interval.

For the annual dividend growth, all the models display a slightly lower dividend growth rate than the sample data. However, the dividend volatilities implied by all the models are lower than that of the sample data. I find that choosing a small dividend volatility parameter $\varphi_{d}$ achieves a better fit in asset pricing moments. As for the higher moments, all models imply small skewness close to the sample value. However, the median values of kurtosis for all models are significantly smaller than the sample data. Finally, the autocorrelation of the dividend growth is matched by all the models reasonably well.

To summarize, the consumption and dividend processes implied by the jump-diffusion models match the first moment of consumption and dividend growth quite well, yet they

have a mixed performance in matching the higher moments of consumption and dividend. However, matching both cash-flow data and asset pricing data is not the main goal of this 
paper, especially when the measurement of cash-flow data is still subject to a large potential bias. Currently consumption is measured as the sum of service and non-durable goods, yet durable goods can also play an important role in asset pricing. Furthermore, the consumption of the stock participants may be a better measure of consumption for pricing assets (see Vissing-Jorgenson 2002). Dividends may also be a biased measure of corporate cash flows, as dividends can be affected by shifts in corporate financial policy that is unrelated to macro fundamentals. Several studies reveal important connections between asset prices and earnings (see Longstaff and Piazzesi 2004, Bansal et al. 2005).

\subsection{Return Predictability by Price-Dividend Ratios}

Bansal and Yaron(2004) suggest that LRR models can explain price-dividend ratios' strong predictability of excess stock returns. The conclusion is further supported by Drechsler and Yaron (2009). From the LRR model's point of view, the strong predictability exists because both stock returns and price-dividend ratios are functions of the time-varying volatility factor(s) and the long-run component in growth, which are highly persistent. However, given that in the model, the consumption and dividend growth rates are also functions of the these state variables, the model may imply high predictability of these two growth rates as well. Furthermore, since the volatility of stock returns, consumption growth, and dividend growth are functions of the volatility factor(s), the LRR model should imply that price-dividend ratios can predict future stock, consumption, and dividend volatility as well. In fact, Beeler and Campbell (2009) point out the counterfactual implications of the LRR model concerning the price-dividend ratios' predictability of levels and volatilities of stock returns, consumption and dividend growth. Since the work of Beeler and Campbell (2009) is based on the canonical model of Bansal and Yaron (2004), whether the conclusion holds for more general models remains in question. In fact, Drechsler and Yaron (2009) shows a much closer fit regarding consumption growth and volatility predictability (although they do not investigate dividend growth and volatility predictability). Here I use the calibrated models 
to reinvestigate this issue and show that the conclusions reached by Beeler et al. (2009) are largely intact.

The predictive regression for $H$ periods future compound excess stock returns is:

$$
\sum_{i=0}^{H-1}\left(\ln R_{t+i, t+i+1}-\ln R_{f, t+i}\right)=\alpha+\beta_{p r e d}(p-d)_{t}+\epsilon_{H t}, H \geq 1
$$

where $R_{t+i, t+i+1}$ represents the market returns from quarter ${ }_{t+i}$ to quarter $_{t+i+1}$. Similarly, the predictive regressions for log consumption and log dividend growth rates are:

$$
\begin{aligned}
\sum_{i=0}^{H-1}\left(\triangle c_{t+i, t+i+1}\right) & =\alpha_{c}+\beta_{\text {pred_c }_{-}}(p-d)_{t}+\epsilon_{H c t}, \\
\text { and } \sum_{i=0}^{H-1}\left(\triangle d_{t+i, t+i+1}\right) & =\alpha_{d}+\beta_{\text {pred_d }}(p-d)_{t}+\epsilon_{H d t} .
\end{aligned}
$$

While regressions of consumption and dividend growth rates are based on quarterly data; the regression for excess stock returns on price-dividend ratios is based on the monthly bivariate Vector Autoregressive Regression (VAR) model with a lag order of one. Hodrick (1992) shows that the VAR model can reduce the bias brought by finite sample and overlapping returns.

In the volatility predictability regressions, I define return volatility as the log of the aggregate realized volatility over the predictive horizon, i.e. $V_{o l+1, t+H}=\frac{1}{2} \ln \Sigma_{h=0}^{H}\left|R V_{t+h-1, t+h}\right|$, where $R V_{t-1, t}=\left[\Sigma_{k=0}^{K-1}\left(p_{t-1+\frac{k+1}{K}-} p_{t-1+\frac{k}{K}}\right)^{2}\right]$ is the realized variance in month $t$. Furthermore, I define consumption and dividend volatilities as measured by the non-parametric method proposed in Bansal et al. (2005) and Beeler and Campbell (2009). Specifically, for each variable $y_{t}$ (which can be quarterly consumption or dividend), $\mathrm{AR}(1)$ regressions of consumption and dividend are run and the absolute values of the residuals $\epsilon_{c t}$ and $\epsilon_{d t}$ are used to characterize the realized volatilities of the consumption and dividend respectively. So the $H$-quarter realized volatility of consumption or dividend is defined as the sum of the 
quarterly realized volatility:

$$
\operatorname{Vol}_{t+1, t+H}=\Sigma_{h=1}^{H}\left|\varepsilon_{y, t+h}\right|, y \in(c, d)
$$

Then the volatility predictive regression is:

$$
\ln \left[\operatorname{Vol}_{t+1, t+H}\right]=\beta_{v 0}+\beta_{v 1}(p-d)_{t}+\xi_{H t}
$$

Panel A of Table 11 reports the empirical data for the regression coefficients, t-ratios, and $\mathrm{R}^{2} \mathrm{~s}$ of the regressions of stock returns, consumption and dividend growth rates on pricedividend ratios at horizons of four, twelve, and twenty quarters. As shown in the table, price-divided ratios can strongly predict stock returns. The predictive power increases as the horizon increases: at the one-year horizon, the regression $\mathrm{R}^{2}$ is $6.1 \%$; at the five-year horizon, the $\mathrm{R}^{2}$ reaches $18.7 \%$. For consumption growth, the regression has a statistically significant predictive coefficient at the one-year horizon, with a regression $\mathrm{R}^{2}$ of $11.8 \%$. The predictability decreases significantly when the horizon increases and becomes non-significant at the three- and five-year horizons. For dividend growth, there is no statistically significant predictability at any horizon.

Panel B of Table 11 reports the regression results of regressing stock volatility, consumption volatility, and dividend volatility on price-dividend ratios. In contrast to what is found in Beeler and Campbell (2010), after the dividend is adjusted for stock repurchases, price-dividend ratios have no predictive power.

Panel A of Table 12 report the regression coefficients, t-ratios, and $\mathrm{R}^{2} \mathrm{~s}$ of stock excess returns and cash-flow growth rates at horizons of 12, 36, and 60 months based on simulations of all the jump-diffusion models. For the predictability of excess returns, I find that the $R^{2} \mathrm{~s}$ of the regressions are similar across all the models but are smaller than the corresponding regression data shown in Table 11 . The $\mathrm{R}^{2} \mathrm{~s}$ in the model are also smaller than the modelimplied $\mathrm{R}^{2} \mathrm{~s}$ in other studies such as Drechsler et al. (2010). The difference may originate 
from the constraints I put on the dynamic structure of the volatility. Among all the models, the SVJ2F_V_B model demonstrates the strongest predictability from price-dividend ratios.

However, all models imply that the price-dividend ratios strongly predict consumption and dividend growth rates, with the predictive power becoming stronger as horizon increase. This result is contrary to the one shown in Table 11 where only short term consumption growth can be predicted. Similar discrepancies exist in the case of predicting dividend growth.

Panel B reports the regression results regarding the price-dividend ratios' predictability of return volatility, consumption volatility, and dividend volatility. Again, there are significant discrepancies between LRR models and the data. Most models imply strong volatility predictability, while the data do not. These mismatches certainly pose difficult questions which future LRR studies must resolve.

\section{Concluding Remarks}

Studies on long-run risks models have shown their great potential to explain several key stylized facts in postwar U.S. asset prices, including high and volatile equity risk premium and high variance risk premium that can possibility predict short term equity return. Among these studies, Drechsler and Yaron (2011) is particularly interesting to us. It suggests that a model with a multifactor stochastic volatility structure, jumps in long-run economic growth, and jumps in volatility can explain equally well variance premium and equity premium, and at the same time generate other desirable fits in asset prices. However, several important economic questions were not fully addressed, such as which jump channel is necessary for generating the variance risk premium and whether the important volatility clustering effect can be generated.

This paper answers these two questions by calibrating a series of jump-diffusion LRR models. The main finding is that these two questions are actually closely related. In par- 
ticular, I find that models with jump in consumption growth can generate large variance premium, but cannot generate a realistic persistence in volatility dynamics. In contrast, models with jumps in long-run growth volatility explain slightly less variance premium, but generate more realistic volatility dynamics. Therefore, if volatility dynamics fitting is one criterion for judging whether an equilibrium pricing model is good or not, then volatility jump channel should be favored.

I find several questions for the LRR model remain unanswered. To begin, the sample data suggest no strong predictability of consumption and dividend by price-dividend ratios, yet most of the calibrated models give opposite conclusions. Additionally, the sample data suggest no predictability of volatility of returns, consumption growth, and dividend growth, yet most of the investigated models imply strong volatility predictability by price-dividend ratios.

These discrepancies may be related to the fact that it is very hard to find direct evidence for the long-run component in aggregate consumption. Aside from the fact that the data for annual consumption are still limited, other factors may also contribute. Vissing-Jørgensen (2002) suggest that the measurement of consumption should either include durable goods or account for the limited stock market participation effect. Hansen and Sargent (2010) suggest that the long-run risk assumption may originate from the model uncertainty of investors. Bonomo et al. (2011) propose that the low predictability in consumption growth can be explained by generalized disappointment aversion. More research is needed in the future to enlighten our understanding of the sources of long-run risks in consumption growth.

\section{Appendix}

\section{A. Solving the Equilibrium Model}

\section{A.1 Fundamental and Pricing Kernel Dynamics}

For a LRR model, the vector $Y_{t}$ includes all state variables of interest in this study. Following Eraker and Shaliastovich (2008), the dynamics of $Y_{t}$ is:

$$
d Y_{t}=\mu\left(Y_{t}\right) d t+\Sigma\left(Y_{t}\right) d W_{t}+\xi_{t} \cdot d N_{t}
$$


where

$$
\begin{gathered}
\mu\left(Y_{t}\right)=M+K Y_{t} \\
\Sigma\left(Y_{t}\right) \Sigma\left(Y_{t}\right)^{\prime}=h+\sum H_{i} Y_{t} .
\end{gathered}
$$

Here $\mathrm{M}$ is a $n \times 1$ vector; $\mathrm{K}$ is a $n \times n$ matrix; $\mathrm{h}$ is a $n \times n$ matrix; and $H_{i \in\{1, \ldots n\}}$ are $n \times n$ matrices. $d W_{t}$ is a Brownian motion vector; $d N_{t}$ represents jump intensity of state variables. They are governed by Poisson processes with time-varying jump intensity. For example, $\operatorname{Prob}\left(d N_{x}=1 \mid \digamma_{t}\right)=l_{X V} V_{t}^{f} d t$ and $\operatorname{Prob}\left(d N_{V}=1 \mid \digamma_{t}\right)=l_{V} V_{t}^{f} d t$. $\xi_{i}$ represents the jump size. The jump size in $x_{t}$ follows a compensated negative Gamma distribution, i.e. $\xi_{x} \sim-\Gamma\left(\mu_{x}, \gamma_{x}\right)+\mu_{x}$, and the jump size in $V_{t}^{f}$ follows a standard Gamma distribution, which is $\xi_{V} \sim \Gamma\left(\mu_{V}, \gamma_{V}\right)$.

I assume the representative agent has a recursive utility function as follows:

$$
U_{t}=\left\{\left(1-e^{-(\ln \delta) d t}\right) C_{t}^{1-\rho}+\left(e^{-(\ln \delta) d t}\right) E_{t}\left(U(t+d t)^{1-\gamma}\right)^{\frac{1-\rho}{1-\gamma}}\right\}^{\frac{1}{1-\rho}}
$$

where $\rho=\frac{1}{\psi}$.

The formula describing the dynamics of $d \log M_{t}$ is:

$$
d \log M_{t}+(1-\theta) d r_{t}+\frac{\theta}{\psi} d \log C_{t}=(\log \delta) \theta d t
$$

similar to the evolution of the pricing kernel in the discrete-time modeling framework.

\section{A.2 Solving the Model}

Under the equilibrium, for the consumption-claim asset (or wealth), we have:

$$
\begin{aligned}
d\left(m_{t}+r_{c, t}\right)= & \theta\left(\Delta v_{t}^{c}+d \log \left(C_{t}\right)+\frac{d t}{\exp \left(v_{t}^{c}\right)}\right) \\
& -\frac{\theta}{\psi} d \log C_{t}+\log (\delta) \theta d t \\
= & 0
\end{aligned}
$$

and for the dividend-claim based asset (or equity), we have

$$
\begin{aligned}
d\left(m_{t}+r_{d, t}\right)= & \theta\left(\Delta v_{t}^{d}+d \log D_{t}+\frac{d t}{\exp \left(v_{t}^{d}\right)}\right) \\
& -\frac{\theta}{\psi} d \log D_{t}+(\log \delta) \theta d t \\
= & 0
\end{aligned}
$$

At the same time, under the log-linear approximation, we can write returns in wealth and in equity as:

$$
\begin{aligned}
& r_{c, t}=k_{0} d t+k_{1} \Delta v_{t}^{c}-\left(1-k_{1}\right) v_{t}^{c} d t+d \log C_{t} \\
& r_{d, t}=k_{0 d} d t+k_{1 d} \Delta v_{t}^{d}-\left(1-k_{1 d}\right) v_{t}^{d} d t+d \log D_{t}
\end{aligned}
$$


Assuming $v_{t}^{c}=A+B Y_{t}, v_{t}^{d}=A_{d}+B_{d} Y_{t}$ and substituting them into the Euler equation A. 4 and A.5 above, we get

$$
\begin{array}{r}
K^{\prime} \chi-\theta\left(1-k_{1}\right) B+0.5 \chi^{\prime} H \chi+l_{1}^{\prime}(\varrho(\chi)-1)=0 \\
\theta\left(\ln \delta+k_{0}-\left(1-k_{1}\right) A\right)+M^{\prime} \chi=0 \\
K^{\prime} \chi_{d}+(\theta-1)\left(k_{1}-1\right) B+\left(k_{1 d}-1\right) B_{d}+0.5 \chi_{d}^{\prime} H \chi_{d}+l_{1}^{\prime}\left(\varrho\left(\chi_{d}\right)-1\right)=0 \\
\theta\left(\ln \delta-(\theta-1)\left(\ln k_{1}+\left(k_{1}-1\right) B^{\prime} \mu_{Y}\right)-\left(\ln k_{1 d}+\left(k_{1 d}-1\right) B_{d}^{\prime} \mu_{Y}+\right.\right. \\
M^{\prime} \chi_{d}+0.5 \chi_{d}^{\prime} h \chi_{d}+l_{0}\left[\rho\left(\chi_{d}\right)-1\right]=0 \\
A_{d}+B_{d}^{\prime} \mu_{Y}=\ln \frac{\kappa_{1, d}}{1-\kappa_{1, d}} .
\end{array}
$$

Here $\chi=\theta\left((1-\rho) \delta_{c}+k_{1} B\right), \chi_{d}=\delta_{d}+k_{1 d} B_{d}-\left(\gamma \delta_{c}+(1-\theta) k_{1} B\right)$, and $\mu_{Y}$ is the unconditional mean of state variables (for $\log C_{t}, \log D_{t}$, the unconditional mean is set to zero).

The coefficients $\kappa_{0}, \kappa_{1}, \kappa_{0 d}, \kappa_{1 d}$ have the following:

$$
\begin{aligned}
\kappa_{1}= & \frac{\exp \left(E\left(v_{t}^{c}\right)\right)}{1+\exp \left(E\left(v_{t}^{c}\right)\right)} \\
& \text { and } \\
\kappa_{0}= & -\ln \left[\left(1-\kappa_{1}\right)_{1}^{1-\kappa_{1}} \kappa_{1}^{\kappa_{1}}\right]
\end{aligned}
$$

and

$$
\begin{aligned}
\kappa_{1 d}= & \frac{\exp \left(E\left(v_{t}^{d}\right)\right)}{1+\exp \left(E\left(v_{t}^{d}\right)\right)} \\
& \text { and } \\
\kappa_{0 d}= & -\ln \left[\left(1-\kappa_{1 d}\right)_{1}^{1-\kappa_{1 d}} \kappa_{1 d}^{\kappa_{1 d}}\right] .
\end{aligned}
$$

These four constants are not known initially, but I can assume reasonable starting values and recursively solve them until the solutions converge.

\section{A.3 Risk-free Rate}

Using the fact that $M_{t} e^{\int_{0}^{t} r(s) d s}$ is a martingale, with Ito's lemma, I can derive the instantaneous risk-free interest rate as

$$
r_{t}=\Phi_{0}+\Phi_{1} Y_{t}
$$

here

$$
\begin{aligned}
& \Phi_{0}=\theta \beta+(\theta-1)\left(\ln k_{1}+\left(k_{1}-1\right) B^{\prime} \mu_{Y_{t}}\right)+M^{\prime} \lambda-\frac{1}{2} \lambda^{\prime} h \lambda, \\
& \Phi_{1}=(1-\theta)\left(k_{1}-1\right) B+K^{\prime} \lambda-\frac{1}{2} \lambda^{\prime} H \lambda-l_{1}^{\prime}(\varrho(-\lambda)-1)
\end{aligned}
$$

where $\lambda=\gamma \delta_{c}+(1-\theta) k_{1} B$ is the price of risks. The calculations of $\Phi_{0}$ and $\Phi_{1}$ follow Eraker (2008) 


\section{A.4 Risk Neutral Dynamics}

The risk neutral dynamics of state variables can be expressed as

$$
d Y_{t}=\left(M^{Q}+K^{Q} Y_{t}\right) d t+\Sigma\left(Y_{t}\right) d W_{t}^{Q}+\xi_{t}^{Q} \cdot d N_{t}^{Q},
$$

where $M^{Q}=M-h \lambda, K^{Q}=K-H \lambda, d W_{t}^{Q}=d W_{t}+\Lambda_{t} d t$ and $\lambda=\gamma \delta_{c}+(1-\theta) k_{1} B$ reflects how different shocks of state variables can affect the change in the stochastic discount factor. $\Lambda_{t}=\Sigma\left(X_{t}\right)^{\prime} \lambda$ can be understood as the price of the diffusion shock.

The jump arrival intensity transformation under the risk-neutral measure are

$$
\begin{aligned}
l_{x V}^{Q} & =\exp \left(-\lambda_{x} \mu_{x}\right)\left(1-\frac{\lambda_{x} \mu_{x}}{\gamma_{x}}\right)^{-\gamma_{x}} l_{x V}, \\
\text { and } l_{V}^{Q} & =\left(1+\frac{\lambda_{v} \mu_{v}}{\gamma_{v}}\right)^{-\gamma_{v}} l_{V} .
\end{aligned}
$$

For jump size distribution, the risk neutral moment generating function as follows:

$$
\begin{aligned}
& \varrho_{x}^{Q}(u)=\exp \left(\mu_{x} u\right)\left(1+\frac{\mu_{x}^{Q} u}{\gamma_{x}^{Q}}\right)^{-\gamma_{x}^{Q}}, \\
& \varrho_{V}^{Q}(u)=\left(1-\frac{\mu_{V}^{Q} u}{\gamma_{V}^{Q}}\right)^{-\gamma_{V}^{Q}},
\end{aligned}
$$

here $\gamma_{x}^{Q}=\gamma_{x}, \mu_{x}^{Q}=\frac{\mu_{x} \gamma_{x}}{\gamma_{x}+\lambda_{x} \mu_{x}}, \gamma_{V}^{Q}=\gamma_{V}, \mu_{V}^{Q}=\frac{\mu_{V} \gamma_{V}}{\gamma_{V}+\lambda_{V} \mu_{V}}$.

\section{A.5 Calculation of the Variance Risk Premium}

As suggested in Duffie et al. (2000) and Eraker (2008), I can take advantage of the fact that $\log$ stock prices are affine functions of the state variables so the moment generating functions for both $\mathrm{P}$ and $\mathrm{Q}$ measures can be expressed in a semi-closed form:

$$
\begin{aligned}
\psi^{i}\left(u, Y_{t}, 0, T\right) & =E_{0}^{i} \exp \left(u \ln S_{T}\right) \\
& =e^{\alpha_{i}(u, T)+\beta_{i}(u, T) Y_{t}}, i \in\{P, Q\},
\end{aligned}
$$

where $\alpha_{i}(u, t)$ and $\beta_{i}(u, t)$ satisfies

$$
\frac{\partial \beta_{i}}{\partial t}=K^{i^{\prime}} \beta+\frac{1}{2} \beta^{\prime} H \beta+l_{1}^{i^{\prime}}\left(\varrho^{i}(\beta)-1\right)
$$

and

$$
\frac{\partial \alpha_{i}}{\partial t}=M^{i^{\prime}} \beta+\frac{1}{2} \beta^{\prime} h \beta+l_{0}^{i^{\prime}}\left(\varrho^{i}(\beta)-1\right),
$$

with the initial conditions of $\alpha_{i}(u, 0)=0$ and $\beta_{i}(u, 0)=u$.

The one-month ahead conditional variances in risk-neutral and physical measures can 
therefore be written as

$$
\begin{aligned}
\operatorname{Var}_{t}^{i}\left[\ln R_{t, t+1}^{i}\right] & =\left.\frac{\partial^{2} \ln \psi^{i}\left(u, Y_{t}, t, t+1\right)}{\partial u^{2}}\right|_{u=0} \\
& =\alpha_{i}^{\prime \prime}(0,1)+\beta_{i}^{\prime \prime}(0,1) Y_{t}^{i}, i \in P, Q .
\end{aligned}
$$

Furthermore, the expectation of stock return quadratic variations $Q V_{t, t+1}$ under both physical and risk-neutral measures can be approximately calculated as the integrated conditional variance, i.e.

$$
\begin{aligned}
E^{i}\left[Q V_{t, t+1}\right] & \simeq E^{i}\left[\sum_{n=1}^{M} \operatorname{Var}_{t+\frac{n}{M}}^{i}\left[\ln R_{t+\frac{n}{M}, t+\frac{n+1}{M}}\right]\right] \\
& \simeq \operatorname{Var}_{t}^{i}\left[\ln R_{t, t+1}\right], i \in\{P, Q\}
\end{aligned}
$$

where

$$
Q V_{t, t+1}=\int_{t}^{t+1} \nu_{s}^{2} d s=\lim _{N \rightarrow \infty} \sum_{i=1}^{N}\left(p_{i+1}-p_{i}\right)^{2} .
$$

The risk-neutral expected variance corresponds to the short-term variance swap rate, which can be represented by the square of the VIX index provided by the CBOE. The physical expected variance can be estimated based on the high-frequency S\&P 500 futures data. The variance risk premium $(V R P)$ is defined as the difference between the expected variance under the two measures; i.e.,

$$
V R P=E^{Q}\left[Q V_{t, t+1}\right]-E^{P}\left[Q V_{t, t+1}\right]
$$

Under the two-factor model, $V R P$ is an affine function of the short-run and long-run volatility factors $V_{t}^{f}$ and $V_{t}^{s}$, while under the one-factor model, it is an affine function of the single volatility factor $V_{t}$.

\section{A.6 Decompose equity risk premium}

Assuming the log pricing kernel can be decomposed into a diffusion part and a jump part, i.e.

$$
\begin{aligned}
m_{t}= & m_{t}^{d}+m_{t}^{j} \\
= & \underbrace{\left(\log (\delta) \theta-\frac{\theta}{\psi} d c_{t}+(\theta-1) r_{c, t}^{d}\right)}_{\text {diffusion }} \\
& +\underbrace{(\theta-1) r_{c, t}^{J}}_{\text {jump }}
\end{aligned}
$$


where $r_{c, t}=r_{c, t}^{d}+r_{c, t}^{J}$ is the return on consumption claim based assets. Under the CampbellShiller assumption, $r_{c, t}$ is a function of wealth-consumption ratios and consumption growth:

$$
r_{c, t}=k_{0} d t+k_{1} \Delta v_{t}^{c}-\left(1-k_{1}\right) v_{t}^{c} d t+d \log C_{t}
$$

Similarly, the log of the market return can also be split into a diffusion term and a jump term and it is also determined by price-dividend ratio and dividend growth.

$$
\begin{aligned}
r_{m, t} & =r_{m, t}^{d}+r_{m, t}^{J} \\
& =k_{0 d} d t+k_{1 d} \Delta v_{t}^{d}-\left(1-k_{1 d}\right) v_{t}^{d} d t+d\left(\log D_{t}\right)
\end{aligned}
$$

Following Drechsler and Yaron (2011), the instantaneous expected equity risk premium is determined by the sum of diffusion and jump risk premiums:

$$
\begin{aligned}
& E_{t}\left(R_{m}-R_{f}\right) \\
= & -\operatorname{Cov}_{t}\left(m_{t+d t}^{d}, r_{m, t+d t}^{d}\right)+ \\
& \ln E_{t}\left[e^{r_{m, t+d t}^{J}}\right]+\ln E_{t}\left[e^{m_{t+d t}^{J}}\right]-\ln E_{t}\left[e^{r_{m, t+d t}^{J}+m_{t+d t}^{J}}\right]
\end{aligned}
$$

Substituting $v_{t}^{c}=A+B Y_{t}$ and $v_{t}^{d}=A_{d}+B_{d} Y_{t}$ into eq.(A.20) and eq. (A.21) gives the diffusion part of the premium. Since both $m_{t+d t}^{d}$ and $r_{m, t+d t}^{d}$ are functions of random shocks of state variables and consumption and dividend growth rates, such as $d W_{x, t}, d W_{v f, t}, d W_{v p, t}, d W_{c, t}$, and $d W_{d, t}$, the compensation of the diffusion risk premium can be decomposed into components contributed to by various risk sources, i.e.

$$
\begin{aligned}
-\operatorname{Cov}_{t}\left(m_{t+d t}^{d}, r_{m, t+d t}^{d}\right)= & \underbrace{\gamma \varphi_{d} \rho_{d c}\left(\delta_{c} V_{t}^{f}+\left(1-\delta_{c}\right) V_{t}^{s}\right)}_{d W_{c}} \\
& +\underbrace{(1-\theta) \kappa_{1} \kappa_{1 d}\left(B_{x} \varphi_{e}+B_{v f} \sigma_{w f} \rho_{x f}\right)\left(B_{d x} \varphi_{e}+B_{d v f} \sigma_{w f} \rho_{x f}\right) V_{t}^{f}}_{d W_{x}} \\
& +\underbrace{(1-\theta) \kappa_{1} \kappa_{1 d} B_{v f} B_{d v f} \sigma_{w}^{f 2}\left(1-\rho_{x f}^{2}\right) V_{t}^{f}}_{d W_{v}^{f}} \\
& +\underbrace{(1-\theta) \kappa_{1} \kappa_{1 d} B_{v s} B_{d v s} \sigma_{w}^{s 2} V_{t}^{s}}_{d W_{v}^{s}}
\end{aligned}
$$

For the SV1F, SVJ1F_G, SVJ1F_V, SVJ2F_G_A, and SVJ2F_V_A models, $\delta_{c}=1$; for the SV2F, SVJ2F_G_B, and SVJ2F_V_B models, $\delta_{c}=0 . \quad B=\left[\bar{B}_{x}, B_{v f}, B_{v s}\right]^{\prime}, B_{d}=$ $\left[B_{d x}, B_{d v f}, B_{d v s}\right]^{\prime}$

The jump part of the premium can be calculated based on the characteristic functions of the jump distribution in $x_{t}$ and $V_{t}^{f}$. For $x_{t}$, it is

$$
\left[\psi_{\mu_{x}, \gamma_{x}}\left(\kappa_{1 d} B_{d x}\right)-1-\psi_{\mu_{x}, \gamma_{x}}\left(\kappa_{1 d} B_{d x}-(1-\theta) \kappa_{1} B_{x}\right)+\psi_{\mu_{x}, \gamma_{x}}\left(-(1-\theta) \kappa_{1} B_{x}\right)\right] l_{X V} V_{t}^{f},
$$

where the characteristic function $\psi_{\mu_{x}, \gamma_{x}}(u)$ for the negative compensated Gamma distribution 
is

$$
\exp \left(\mu_{x} u\right)\left(1+\frac{\mu_{x} u}{\gamma_{x}}\right)^{-\gamma_{x}}
$$

for jump in volatility, it is

$$
\left[\psi_{\mu_{v}, \gamma_{v}}\left(\kappa_{1 d} B_{d v f}\right)-1-\psi_{\mu_{v}, \gamma_{v}}\left(\kappa_{1 d} B_{d v f}-(1-\theta) \kappa_{1} B_{v f}\right)+\psi_{\mu_{v}, \gamma_{v}}\left(-(1-\theta) \kappa_{1} B_{v f}\right)\right] l_{V} V_{t}^{f}
$$

where the characteristic function $\psi_{\mu_{v}, \gamma_{v}}(u)$ for the Gamma distribution,is

$$
\left(1-\frac{\mu_{x} u}{\gamma_{x}}\right)^{-\gamma_{x}}
$$

\section{B. Model Calibration}

To calibrate the model parameters, I choose a systematic strategy based on the Simulated Methods of Moments (SMM) (Duffie et al.1993 , Gourieroux et al.1996 ). ${ }^{17}$ Here is the procedure for carrying out the SMM calibration.

Step 1: Collecting the target moments of the data, I split the moments into two parts, the first part are moments that are based on the data from 1951 to 2010, while the second part are moments based on the volatility data from 1990 to 2010. Specially, I write the vector of moments $\tilde{y}(t)$ as

$$
\tilde{y}(t)=\left[\tilde{y}_{1}(t), \tilde{y}_{2}(t)\right]
$$

where

$$
\tilde{y}_{1}(t)=\left(\begin{array}{c}
R_{f t},(p-d)_{t},(\sqrt{R V})_{t} \\
{\left[R_{f t}-E\left(R_{f t}\right)\right]^{2},\left[(\sqrt{R V})_{t}-E(\sqrt{R V})\right]^{2}} \\
{\left[(p-d)_{t}-E(p-d)\right]^{2}} \\
{\left[R_{f t}-E\left(R_{f t}\right)\right]\left[R_{f, t-1}-E\left(R_{f t}\right)\right]}
\end{array}\right)
$$

and

$$
\tilde{y}_{2}(t)=\left(\begin{array}{c}
\left.V I X_{t},\left[V I X_{t}-E(V I X)\right]^{2}\right), \\
{\left[V I X_{t}-E(V I X)\right]\left[V I X_{t-1}-E(V I X)\right]} \\
{\left[V I X_{t}-E(V I X)\right]\left[V I X_{t-6}-E(V I X)\right]} \\
{\left[V I X_{t}-E(V I X)\right]\left[\frac{1}{3} \sum_{n=11}^{13} V I X_{t-n}-E(V I X)\right]}
\end{array}\right)
$$

the first set of moments $\tilde{y}_{1}(t)$ includes the first and second moments of the risk-free rate, the log price-dividend ratio, and the realized volatility together with the first autocovariance moment of the risk-free rate, while the second set of $\tilde{y}_{2}(t)$ includes the moments based on the VIX data including the lag-1, lag-6 and lag-12 autocovariances ( the lag-12 autocovariances are estimated by averaging the lag-11, lag-12, and lag-13 autocovariances).

To overcome the issue of the shorter periods of options data as compared to other asset market data, a procedure from Singleton (2006) is adopted to construct an overidentification vector of $M_{O I D}\left(m, \tilde{y}_{t}\right)$ which includes data from both periods. The estimated moments minimize the objective function

$$
\tilde{m}\left(\tilde{y}_{t}^{d a t a}\right)=\arg \min _{m=\left[m_{1}, m_{2}\right]} M_{O I D}\left(m, \tilde{y}_{t}^{\text {data }}\right)^{\prime} W_{T} M_{O I D}\left(m, \tilde{y}_{t}^{\text {data }}\right),
$$

\footnotetext{
${ }^{17}$ Part of my code is adapted from Fackler and Tastan (2008).
} 
where $M_{O I D}\left(m, \tilde{y}^{\text {data }}\right)=\left[\frac{1}{T_{1}} \sum_{1}^{T_{1}} \tilde{y}_{1}^{\text {data }}(t)-m_{1}, \frac{1}{T_{2}} \sum_{T_{1}+1}^{T_{1}+T_{2}} \tilde{y}_{1}^{\text {data }}(t)-m_{1}, \frac{1}{T_{2}} \sum_{1}^{T_{2}} \tilde{y}_{2}^{\text {data }}(t)-m_{2}\right]$ is the overidentification vector. The estimation of $W_{T}$ follows a standard two-stage process.

Step 2: For a given parameter set $\theta$, the state variable dynamics are discretized and simulated and the corresponding asset prices such as the short rates and the price dividend ratios are calculated based on the equilibrium solution at each period. Each simulation contains a sample size of 20,000 months. In the simulation, the same proportion of the VIX data is ignored as when estimating the real data. ${ }^{18}$

Step 3: The overidentification vector $M_{O I D}\left(\tilde{m}\left(\tilde{y}_{t}, \hat{y}_{\text {simu }}(\theta)\right)\right.$ is constructed and the optimal calibration $\theta^{0}$ is the solution to minimize the criteria function

$$
M_{O I D}\left(\tilde{m}\left(\tilde{y}_{t}\right), \hat{y}_{\text {simu }}(\theta)\right)^{\prime} \Omega_{T} M_{O I D}\left(\tilde{m}\left(\tilde{y}_{t}\right), \hat{y}_{\text {simu }}(\theta)\right) .
$$

Here the optimal weighting matrix of $\Omega_{T}$ is estimated using a Newey-west estimator and a Bartlett weighting scheme with a lag length of 10.

Step 4: To compare the quality of fit across different models, I calculate the overidentification J-statistics and adjust them based on the fact that the moments are obtained by simulation instead of analytical solution. The typical adjustment based on the ratio of the simulated data length (20,000 months) to the realized data length (about 720 months) is applied. Since the simulation length is more than 20 times that of the actual data length, the adjustment is fairly small. For testing on moments that include correlations in realized volatility, the procedure is the same except that $\tilde{y}_{1}(t)$ now also includes the lag-1, lag-6, and lag12 autocovariance moments in realized volatility $\left[\sqrt{R V_{t}}-E(\sqrt{R V})\right]\left[\sqrt{R V_{t-1}}-E(\sqrt{R V})\right]$, $\left[\sqrt{R V_{t}}-E(\sqrt{R V})\right]\left[\sqrt{R V_{t-6}}-E(\sqrt{R V})\right]$, and $\frac{1}{3} \sum_{i=11}^{13}\left[\sqrt{R V_{t}}-E(\sqrt{R V})\right]\left[\sqrt{R V_{t-i}}-E(\sqrt{R V})\right]$.

\section{References}

Andersen, T., T. Bollerslev, and F. Diebold (2007). Roughing it up: Including jump components in the measurement, modeling, and forecasting of return volatility. The Review of Economics and Statistics 89(4), 701-720.

Bansal, R., V. Khatchatrian, and A. Yaron (2005). Interpretable asset markets? European Economic Review 49(3), 531-560.

Bansal, R., D. Kiku, and A. Yaron (2006). Risks for the long run: Estimation and inference. Manuscript, Department of Economics, Duke University, Durham NC.

Bansal, R., D. Kiku, and A. Yaron (2007). A note on the economics and statistics of predictability: A long run risks perspective. unpublished paper, Duke University and

\footnotetext{
${ }^{18}$ I use the Euler scheme to discretize the continuous time dynamics. The time interval is at a frequency of $1 / 20$ of a month, roughly corresponding to a daily frequency. The simulated variables are then aggregated at a monthly level.To ensure that a discretizaton error is small, I compare the simulation result of $1 / 20$ of a month and that of $1 / 40$ of a month to find that the results are quite similar. We also compare the simulated option price based on the discretization of $1 / 40$ of a month with one based on a semi-closed form, continuous time calculation, and the two prices are also quite close, again confirming the adequacy of my discretization choice. During the simulation, we start with the initial state variables at their unconditional means and then discard the first 1 million steps. This is a practical way of randomizing the initial condition so that the simulated process will be stationary.
} 
UniEs versity of Pennsylvania.

Bansal, R. and I. Shaliastovich (2009). Confidence risk and asset prices. Technical report, National Bureau of Economic Research.

Bates, D. (2000). Post-'87 crash fears in the S\&P 500 futures option market. Journal of Econometrics 94(1-2), 181-238.

Beeler, J. and J. Campbell (2009). The long-run risks model and aggregate asset prices: an empirical assessment. NBER Working paper.

Bekaert, G. and E. Engstrom (2009). Asset return dynamics under bad environment good environment fundamentals. Technical report, National Bureau of Economic Research.

Bollerslev, T. and V. Todorov (2011). Tails, fears, and risk premia. The Journal of Finance 66 (6), 2165-2211.

Bonomo, M., R. Garcia, N. Meddahi, and R. Tédongap (2011). Generalized disappointment aversion, long-run volatility risk, and asset prices. Review of Financial Studies $24(1), 82$.

Boudoukh, J., R. Michaely, M. Richardson, and M. Roberts (2007). On the importance of measuring payout yield: Implications for empirical asset pricing. The Journal of Finance 62(2), 877-915.

Calvet, L. and A. Fisher (2008). Multifractal volatility: theory, forecasting, and pricing. Academic Pr.

Chacko, G. and L. Viceira (2003). Spectral GMM estimation of continuous-time processes. Journal of Econometrics 116(1-2), 259-292.

Chernov, M., A. Ronald Gallant, E. Ghysels, and G. Tauchen (2003). Alternative models for stock price dynamics. Journal of Econometrics 116(1-2), 225-257.

Corsi, F. (2009). A simple approximate long-memory model of realized volatility. Journal of Financial Econometrics.

Drechsler, I. and A. Yaron (2011). What's vol got to do with it. Review of Financial Studies 24(1), 1-45.

Duffie, D., J. Pan, and K. Singleton (2000). Transform analysis and asset pricing for affine jump-diffusions. Econometrica 68(6), 1343-1376.

Duffie, D. and K. Singleton (1993). Simulated moments estimation of Markov models of asset prices. Econometrica: Journal of the Econometric Society 61(4), 929-952.

Engle, R., E. Ghysels, and B. Sohn (2008). On the economic sources of stock market volatility. In AFA 2008 New Orleans Meetings Paper.

Engle, R. and G. Lee (1999). A long-run and short-run component model of stock return volatility. Cointegration, Causality and Forecasting: A Festschrift in Honour of Clive Granger.

Eraker, B. (2004). Do stock prices and volatility jump? Reconciling evidence from spot and option prices. The Journal of Finance 59(3), 1367-1404.

Eraker, B. (2008). The volatility premium. Manuscript. 
Eraker, B. and I. Shaliastovich (2008). An equilibrium guide to designing affine pricing models. Mathematical Finance 18(4), 519-543.

Fackler, P. and H. Tastan (2008). A Framework for Indirect Inference.

Feunou, B., J. Fontaine, A. Taamouti, and R. Tédongap (2012). Risk premium, variance premium and the maturity structure of uncertainty. The Bank of Canada Working Paper.

Ghysels, E., P. Santa-Clara, and R. Valkanov (2005). There is a risk-return trade-off after all. Journal of Financial Economics 76(3), 509-548.

Gourieroux, C. and A. Monfort (1996). Simulation-based econometric methods. Oxford University Press, USA.

Hansen, L. and T. Sargent (2010). Fragile beliefs and the price of uncertainty. Quantitative Economics 1(1), 129-162.

Longstaff, F. and M. Piazzesi (2004). Corporate earnings and the equity premium. Journal of Financial Economics 74(3), 401-421.

Newey, W. K. and K. D. West (1987). A simple, positive semi-definite, heteroskedasticity and autocorrelation consistent covariance matrix. Econometrica: Journal of the Econometric Society, 703-708.

Pan, J. (2002). The jump-risk premia implicit in options: evidence from an integrated time-series study. Journal of Financial Economics 63(1), 3-50.

Shaliastovich, I. (2009). Learning, confidence and option prices. Technical report, working paper.

Singleton, K. (2006). Empirical dynamic asset pricing: model specification and econometric assessment. Princeton Univ Pr.

Vissing-Jørgensen, A. (2002). Limited asset market participation and the elasticity of intertemporal substitution. Journal of Political Economy 110(4), 825-853.

Zhou, G. and Y. Zhu (2009). A long-run risks model with long-and short-run volatilities: explaining predictability and volatility risk premium. Unpublished working paper. Washington University. 


\section{Table 1: Summary Statistics}

This table presents the summary statistics of the empirical data. All variables are reported in annualized percentage form whenever appropriate except that RV, $\mathrm{VIX}^{2}$, and $\mathrm{VRP}_{H A R}$ are recorded in units of $1 / 12$ of the annual variance.

\begin{tabular}{|c|c|c|c|c|c|c|c|}
\hline \multicolumn{8}{|c|}{ Annual: 1951-2010 } \\
\hline & Mean & Std.dev. & Skewness & Kurtosis & $\mathrm{AC}(1)$ & $\mathrm{AC}(6)$ & $\mathrm{AC}(12)$ \\
\hline$\Delta c$ & 2.03 & 1.22 & -0.59 & 3.47 & 0.38 & & \\
\hline$\Delta d_{c a s h}$ & 1.00 & 6.90 & 0.42 & 4.85 & 0.18 & & \\
\hline$\Delta d_{\text {payout }}$ & 2.52 & 12.52 & 0.18 & 5.51 & 0.35 & & \\
\hline \multicolumn{8}{|c|}{ Monthly: $1951 \mathrm{~m} 1$ to $2010 \mathrm{~m} 7$} \\
\hline $\mathrm{R}_{f}$ & 1.68 & 2.03 & 0.06 & 3.49 & 0.88 & & \\
\hline $\log (\mathrm{P} / \mathrm{D})$ & 3.17 & 0.29 & -0.24 & 2.04 & 0.98 & & \\
\hline $\mathrm{R}_{m}-\mathrm{R}_{f}$ & 6.70 & 14.76 & -0.40 & 4.68 & 0.05 & & \\
\hline $\mathrm{RV}^{*}$ & 19.78 & 39.87 & 11.32 & 166.21 & 0.40 & 0.13 & 0.08 \\
\hline RVol & 13.38 & 7.64 & 3.73 & 29.74 & 0.63 & 0.37 & 0.28 \\
\hline \multicolumn{8}{|c|}{ Monthly: 1990m1-2010m7 } \\
\hline $\mathrm{RV}_{1990-2010}^{*}$ & 29.71 & 49.36 & 7.98 & 87.2 & 0.55 & 0.11 & 0.07 \\
\hline $\mathrm{VIX}^{2 *}$ & 39.75 & 36.47 & 3.33 & 18.92 & 0.82 & 0.33 & 0.23 \\
\hline RVol & 16.62 & 8.98 & 3.01 & 19.13 & 0.68 & 0.33 & 0.26 \\
\hline VIX & 20.35 & 7.94 & 1.57 & 6.87 & 0.86 & 0.51 & 0.39 \\
\hline $\mathrm{VRP}_{H A R-R V}$ & 13.87 & 23.70 & 4.37 & 35.68 & 0.38 & 0.08 & 0.13 \\
\hline
\end{tabular}

*:unit of $1 / 12$ of the annualized variance 
Table 2: Empirical Predictability of Stock Returns by Variance Risk Premium

This table presents the coefficients, t-statistics, and $\mathrm{R}^{2} \mathrm{~s}$ of regression of excess returns on variance risk premium. Regression methods are VAR and OLS. Variance risk premiums are estimated based on the difference between VIX ${ }^{2}$ and the physical expected variance measured by the HAR-RV method. The monthly data is from 1990.1 to 2007.12 and from 1990.1 to 2010.7 The returns are defined as the mean excess returns with horizons of 1 month, 3 months, 6 months, 9 months and 12 months.

\begin{tabular}{ccccccc|cccccc}
\hline \hline Periods & \multicolumn{3}{c}{$1990-2007$} & \multicolumn{3}{c|}{$1990-2010$} & \multicolumn{3}{c}{$1990-2007$} & \multicolumn{3}{c}{$1990-2010$} \\
\hline & $\hat{\beta}$ & $\hat{\mathrm{t}}$ & $\hat{\mathrm{R}}^{2}(\%)$ & $\hat{\beta}$ & $\hat{\mathrm{t}}$ & $\hat{\mathrm{R}}^{2}(\%)$ & $\hat{\beta}$ & $\hat{\mathrm{t}}$ & $\hat{\mathrm{R}}^{2}(\%)$ & $\hat{\beta}$ & $\hat{\mathrm{t}}$ & $\hat{\mathrm{R}}^{2}(\%)$ \\
\hline \multicolumn{3}{c}{ VRP measure based on HAR-RV (VAR) } & \multicolumn{3}{c}{ VRP measure based on HAR-RV (OLS) } \\
\hline \multirow{2}{*}{$\begin{array}{c}\text { 1 month } \\
3 \text { months }\end{array}$} & 0.037 & 1.67 & 2.3 & -0.001 & -0.06 & 0.0 & 0.037 & 3.27 & 2.3 & -0.001 & -0.05 & 0.0 \\
6 months & 0.064 & 1.93 & 2.4 & 0.005 & 0.17 & 0.0 & 0.107 & 4.67 & 6.9 & 0.021 & 0.43 & 0.4 \\
9 months & 0.069 & 1.92 & 1.0 & 0.006 & 0.20 & 0.0 & 0.136 & 2.38 & 3.7 & 0.068 & 1.44 & 1.2 \\
12 months & 0.069 & 1.92 & 0.8 & 0.006 & 0.20 & 0.0 & 0.114 & 1.66 & 1.8 & 0.070 & 1.55 & 0.9 \\
\hline \hline
\end{tabular}


Table 3: Calibration of the Diffusion-only Long-run Risks Models

This table reports calibration results of diffusion-only LRR models. Panel A reports the parameters that are preset. Panel B reports the parameters that are systematically calibrated. The table also reports the overidentification J-statistics describing the overall model fit. All the parameter units are at monthly frequencies.

Panel A: Preset Parameters

\begin{tabular}{ccc}
\hline \hline Parameter & SV1F & SV2F \\
\hline$\delta$ & 0.999 & 0.999 \\
$\mu_{c}$ & 0.0017 & 0.0017 \\
$\mu_{d}$ & 0.002 & 0.002 \\
$\phi_{d}$ & 3 & 3 \\
$\rho_{d c}$ & 0.4 & 0.4 \\
$\rho_{x f}$ & -0.8 & -0.8 \\
\hline \hline
\end{tabular}

Panel B: Systematically Calibrated Parameters

\begin{tabular}{ccc}
\hline \hline Parameter & SV1F & SV2F \\
\hline$\varphi_{d}$ & 6.5 & 6.5 \\
$\gamma$ & 9.32 & 7.15 \\
$\psi$ & 1.54 & 1.71 \\
$\kappa_{x}$ & 0.003 & 0.009 \\
$\varphi_{e}$ & 0.016 & 0.014 \\
$\sigma_{w}^{f}\left(\times 10^{4}\right)$ & 32.2 & 15.28 \\
$\kappa_{v}^{f}$ & 0.28 & 1.40 \\
$\bar{V}_{f}\left(\times 10^{5}\right)$ & 2.18 & - \\
$\bar{V}_{p}\left(\times 10^{5}\right)$ & - & 0.15 \\
$\sigma_{w}^{p}\left(\times 10^{4}\right)$ & - & 3.04 \\
$\kappa_{v}^{p}$ & - & 0.064 \\
\hline OID & 677.1 & 515.3 \\
\hline \hline
\end{tabular}


Table 4: Moment Matches for the SV1F and SV2F LRR Models

This table displays matches in key moments between the SV1F and SV2F models and the monthly U.S. data. The reported value are medians from 1000 simulations with each spanning a period of 60 years. In the data column, the numbers in the brackets are the adjusted averages taking into account the different spanning periods between the stock data and the VIX data. In the model columns, the numbers in the brackets correspond to $5 \%$ and $95 \%$ quantiles for the finite sample simulations.

\begin{tabular}{|c|c|c|c|}
\hline & Data & SV1F & SV2F \\
\hline $\mathrm{E}\left(\mathrm{R}_{f}\right)$ & $1.68(1.51)$ & $\begin{array}{l}1.47 \\
{[0.40,2.52]}\end{array}$ & $\begin{array}{l}1.84 \\
{[1.02,2.54]}\end{array}$ \\
\hline$\sigma\left(\mathrm{R}_{f}\right)$ & $2.03(1.61)$ & $\begin{array}{l}1.21 \\
{[0.98,1.52]}\end{array}$ & $\begin{array}{l}0.93 \\
{[0.71,1.32]}\end{array}$ \\
\hline $\mathrm{AC} 1\left(\mathrm{R}_{f}\right)$ & $0.88(0.95)$ & $\begin{array}{l}0.79 \\
{[0.72,0.86]}\end{array}$ & $\begin{array}{l}0.90 \\
{[0.68,0.90]}\end{array}$ \\
\hline$E(p-d)$ & $3.17(3.19)$ & $\begin{array}{l}2.85 \\
{[2.54,3.15]}\end{array}$ & $\begin{array}{l}3.24 \\
{[2.99,3.45]}\end{array}$ \\
\hline$\sigma(\mathrm{p}-\mathrm{d})$ & $0.29(0.27)$ & $\begin{array}{l}0.16 \\
{[0.10,0.27]}\end{array}$ & $\begin{array}{l}0.22 \\
{[0.14,0.34]}\end{array}$ \\
\hline $\mathrm{E}(\mathrm{RVol})$ & $13.38(13.86)$ & $\begin{array}{l}12.72 \\
{[11.79,13.68]}\end{array}$ & $\begin{array}{l}11.92 \\
{[10.58,13.65]}\end{array}$ \\
\hline $\mathrm{AC}(\mathrm{RVol})$ & 0.63 & $\begin{array}{l}0.70 \\
{[0.64,0.74]}\end{array}$ & $\begin{array}{l}0.65 \\
{[0.58,0.72]}\end{array}$ \\
\hline $\mathrm{E}(\mathrm{VIX})$ & $20.35(18.11)$ & $\begin{array}{l}13.64 \\
{[12.25,15.03]}\end{array}$ & $\begin{array}{l}12.62 \\
{[10.59,15.44]}\end{array}$ \\
\hline $\mathrm{AC} 1(\mathrm{VIX})$ & $0.86(0.86)$ & $\begin{array}{l}0.72 \\
{[0.63,0.80]}\end{array}$ & $\begin{array}{l}0.78 \\
{[0.66,0.87]}\end{array}$ \\
\hline AC6(VIX) & $0.51(0.58)$ & $\begin{array}{l}0.13 \\
{[-0.04,0.34]}\end{array}$ & $\begin{array}{l}0.48 \\
{[0.25,0.67]}\end{array}$ \\
\hline AC12(VIX) & $0.39(0.48)$ & $\begin{array}{l}0.00 \\
{[-0.16,0.18]}\end{array}$ & $\begin{array}{l}0.27 \\
{[0.01,0.51]}\end{array}$ \\
\hline$R_{m}-R_{f}$ & 0.07 & $\begin{array}{l}0.07 \\
{[0.05,0.10]}\end{array}$ & $\begin{array}{l}0.05 \\
{[0.03,0.08]}\end{array}$ \\
\hline$V R P^{*}$ & $13.87(11.01)$ & $\begin{array}{l}1.98 \\
{[-0.51,2.44]}\end{array}$ & $\begin{array}{l}0.81 \\
{[-2.40,3.54]}\end{array}$ \\
\hline
\end{tabular}

*: VRP is in the unit of $1 / 12$ of the annualized variance 
Table 5: Calibration of the Jump-Diffusion Long-run Risks Models

This table reports calibration results of jump-diffusion LRR models. Panel A reports preset parameters; Panel B reports calibrated parameters. The table also reports the overidentification J-statistics which describe the quality of the overall model fit. OID reports the J-statistics for the moments included in the calibration; $\mathrm{OID}_{A C 1(R V o l)}$ reports the J-statistics for the same calibrated models, but for different asset moments that also include the 1-month autocorrelation in the realized volatility in addition to the moments used for calibration; $\operatorname{OID}_{A C 1,6,12(R V o l)}$ reports the J-statistics for the same models and for the moments that also include the 1-month, 6-month, and 12-month autocorrelations in the realized volatility. All the parameters are in monthly frequencies.

Panel A: Preset Parameters

\begin{tabular}{|c|c|c|c|c|c|c|}
\hline Parameter & SVJ1F_G & SVJ1F_V & SVJ2F_G_A & SVJ2F_V_A & SVJ2F_G_B & SVJ2F_G_B \\
\hline$\delta$ & 0.999 & 0.999 & 0.999 & 0.999 & 0.999 & 0.999 \\
\hline$\mu_{c}$ & 0.0017 & 0.0017 & 0.0017 & 0.0017 & 0.0017 & 0.0017 \\
\hline$\mu_{d}$ & 0.002 & 0.002 & 0.002 & 0.002 & 0.002 & 0.002 \\
\hline$\phi_{d}$ & 3 & 3 & 3 & 3 & 3 & 3 \\
\hline$\rho_{d c}$ & 0.4 & 0.4 & 0.4 & 0.4 & 0.4 & 0.4 \\
\hline$\rho_{x f}$ & -0.8 & -0.8 & -0.8 & -0.8 & -0.8 & -0.8 \\
\hline$l_{X V}$ & 4000 & 0 & 4000 & 0 & 4000 & 0 \\
\hline$\gamma_{x}$ & 1 & 1 & 1 & 1 & 1 & 1 \\
\hline$l_{V}$ & 0 & 500 & 0 & 500 & 0 & 500 \\
\hline$\gamma_{V}$ & 1 & 1 & 1 & 1 & 1 & 1 \\
\hline
\end{tabular}

Panel B: Systematically Calibrated Parameters

\begin{tabular}{|c|c|c|c|c|c|c|}
\hline Parameter & SVJ1F_G & $\mathrm{SVJ}_{1} \mathrm{~F}_{-} \mathrm{V}$ & SVJ2F_G_A & $\mathrm{SVJ} 2 \mathrm{~F}_{-} \mathrm{V}_{-} \mathrm{A}$ & SVJ2F_G_B & SVJ2F_V_B \\
\hline$\varphi_{d}$ & 5 & 5 & 8 & 8 & 5 & 5 \\
\hline$\gamma$ & 5.66 & 5.97 & 6.31 & 7.93 & 5.90 & 6.27 \\
\hline$\psi$ & 1.77 & 1.76 & 1.71 & 1.53 & 1.68 & 1.49 \\
\hline$\kappa_{x}$ & 0.009 & 0.010 & 0.006 & 0.005 & 0.017 & 0.011 \\
\hline$\varphi_{e}$ & 0.024 & 0.040 & 0.031 & 0.020 & 0.058 & 0.052 \\
\hline$\sigma_{w}^{f}\left(\times 10^{4}\right)$ & 33.21 & 2.07 & 20.20 & 2.90 & 36.92 & 2.84 \\
\hline$\kappa_{v}^{(f)}$ & 0.23 & 0.21 & 0.24 & 0.31 & 0.51 & 0.35 \\
\hline $\bar{V}_{f}\left(\times 10^{5}\right)$ & 2.63 & 2.42 & - & - & - & - \\
\hline $\bar{V}_{s}\left(\times 10^{5}\right)$ & - & - & 0.87 & 1.54 & 1.43 & 1.36 \\
\hline$\sigma_{w}^{s}\left(\times 10^{4}\right)$ & - & - & 1.83 & 2.91 & 2.80 & 2.67 \\
\hline$\kappa_{v}^{s}$ & - & - & 0.017 & 0.010 & 0.012 & 0.012 \\
\hline$\mu_{x}\left(\times 10^{4}\right)$ & 3.92 & - & 4.17 & - & 8.46 & - \\
\hline$\mu_{V}\left(\times 10^{5}\right)$ & - & 14.07 & - & 17.53 & - & 19.87 \\
\hline OID & 102.5 & 84.1 & 86.7 & 81.8 & 44.6 & 79.1 \\
\hline $\mathrm{OID}_{A C 1}(R V o l)$ & 150.5 & 102.8 & 110.4 & 102.4 & 221.5 & 83.9 \\
\hline $\mathrm{OID}_{A C 1,6,12(R V o l)}$ & 209.4 & 167.7 & 159.0 & 109.3 & 278.4 & 112.2 \\
\hline
\end{tabular}


Table 6: Moment Matches of the Jump-Diffusion LRR Models

This table displays matches in key moments between the calibrated jump-diffusion models and the monthly U.S. data. The reported values are medians from 1000 simulations with each spanning a period of 60 years. In the data column, the numbers in the brackets are the adjusted averages taking into account the different spanning periods between the stock data and the VIX data. In the model columns, the numbers in the brackets correspond to $5 \%$ and $95 \%$ quantiles for the finite sample simulations.

Panel A: Asset Moments (excluding volatility dynamics)

\begin{tabular}{|c|c|c|c|c|c|c|c|}
\hline & Data & SVJ1F_G & $\mathrm{SVJ1F}_{-} \mathrm{V}$ & SVJ2F_G_A & $\mathrm{SVJ} 2 \mathrm{~F}_{-} \mathrm{V}_{-} \mathrm{A}$ & SVJ2F_G_B & $\mathrm{SVJ} 2 \mathrm{~F}{ }_{-} \mathrm{V}_{-} \mathrm{B}$ \\
\hline \multirow[t]{2}{*}{$\mathrm{E}\left(\mathrm{R}_{f}\right)$} & $1.68(1.51)$ & 1.58 & 1.68 & 1.64 & 2.05 & 1.82 & 2.09 \\
\hline & & {$[0.63,2.35]$} & {$[0.86,2.44]$} & {$[0.83,2.34]$} & {$[1.18,2.80]$} & {$[0.95,2.48]$} & {$[1.21,2.91]$} \\
\hline \multirow[t]{2}{*}{$\sigma\left(\mathrm{R}_{f}\right)$} & $2.03(1.61)$ & 1.14 & 1.25 & 1.01 & 1.05 & 1.21 & 1.14 \\
\hline & & {$[0.89,1.59]$} & {$[1.06,1.57]$} & {$[0.77,1.39]$} & {$[0.63,1.55]$} & {$[0.87,1.69]$} & {$[0.76,1.91]$} \\
\hline \multirow[t]{2}{*}{$\mathrm{AC} 1\left(\mathrm{R}_{f}\right)$} & $0.88(0.95)$ & 0.87 & 0.87 & 0.86 & 0.81 & 0.89 & 0.88 \\
\hline & & {$[0.81,0.93]$} & {$[0.82,0.92]$} & {$[0.80,0.92]$} & {$[0.74,0.91]$} & {$[0.81,0.94]$} & {$[0.79,0.95]$} \\
\hline \multirow[t]{2}{*}{$E(p-d)$} & $3.17(3.19)$ & 3.19 & 3.21 & 3.16 & 2.98 & 3.26 & 3.24 \\
\hline & & {$[2.92,3.42]$} & {$[2.97,3.43]$} & {$[2.89,3.40]$} & {$[2.70,3.22]$} & {$[3.08,3.37]$} & {$[3.03,3.42]$} \\
\hline \multirow[t]{2}{*}{$\sigma(\mathrm{p}-\mathrm{d})$} & $0.29(0.27)$ & 0.23 & 0.23 & 0.22 & 0.21 & 0.21 & 0.22 \\
\hline & & {$[0.15,0.38]$} & {$[0.16,0.34]$} & {$[0.14,0.37]$} & {$[0.15,0.34]$} & {$[0.14,0.31]$} & {$[0.14,0.34]$} \\
\hline \multirow[t]{2}{*}{$\mathrm{E}(\mathrm{RVol})$} & $13.38(13.86)$ & 14.09 & 14.15 & 12.91 & 16.25 & 13.29 & 13.00 \\
\hline & & {$[12.79,15.41]$} & {$[13.95,14.35]$} & {$[11.09,14.90]$} & {$[13.81,19.77]$} & {$[11.09,16.22]$} & {$[10.89,15.65]$} \\
\hline \multirow[t]{2}{*}{$\mathrm{E}(\mathrm{VIX})$} & $20.35(18.11)$ & 17.52 & 16.90 & 16.45 & 19.02 & 16.89 & 15.93 \\
\hline & & {$[15.58,19.86]$} & {$[16.72,17.10]$} & {$[13.32,20.51]$} & {$[14.81,24.49]$} & {$[12.88,22.47]$} & {$[12.04,21.12]$} \\
\hline \multirow[t]{2}{*}{$R_{m}-R_{f}$} & 0.07 & 0.06 & 0.06 & 0.06 & 0.06 & 0.06 & 0.05 \\
\hline & & {$[0.03,0.09]$} & {$[0.03,0.09]$} & {$[0.04,0.09]$} & {$[0.03,0.10]$} & {$[0.03,0.09]$} & {$[0.03,0.08]$} \\
\hline \multirow[t]{2}{*}{$V R P^{*}$} & $13.87(11.01)$ & 9.03 & 7.12 & 8.66 & 8.14 & 9.05 & 7.06 \\
\hline & & {$[6.59,13.08]$} & {$[7.08,7.21]$} & {$[4.54,16.55]$} & {$[2.39,17.41]$} & {$[3.58,20.15]$} & {$[2.20,16.76]$} \\
\hline
\end{tabular}

\footnotetext{
* VRP is in the unit of $1 / 12$ of the annualized variance
} 
Table 6: Matches in Moments for the Jump-Diffusion LRR Models: Continued Panel B: Asset Moments: Volatility Dynamics

\begin{tabular}{llllllll}
\hline \hline & Data & SVJ1F_G & SVJ1F_V & SVJ2F_G_A & SVJ2F_V_A & SVJ2F_G_B & SVJ2F_V_B \\
\hline AC1(VIX) & $0.86(0.86)$ & 0.76 & 0.85 & 0.78 & 0.88 & 0.68 & 0.88 \\
& & {$[0.66,0.84]$} & {$[0.83,0.86]$} & {$[0.69,0.86]$} & {$[0.79,0.96]$} & {$[0.56,0.80]$} & {$[0.79,0.98]$} \\
AC6(VIX) & $0.51(0.58)$ & 0.18 & 0.42 & 0.25 & 0.55 & 0.25 & 0.52 \\
& & {$[-0.01,0.40]$} & {$[0.35,0.48]$} & {$[0.03,0.47]$} & {$[0.25,0.82]$} & {$[0.03,0.53]$} & {$[0.23,0.87]$} \\
AC12(VIX) & \multirow{2}{*}{$0.39(0.48)$} & 0.02 & 0.35 & 0.10 & 0.47 & 0.19 & 0.43 \\
& & {$[-0.16,0.23]$} & {$[0.18,0.41]$} & {$[-0.12,0.32]$} & {$[0.15,0.73]$} & {$[-0.02,0.47]$} & {$[0.08,0.77]$} \\
AC1(RVol) & 0.64 & 0.48 & 0.48 & 0.48 & 0.64 & 0.33 & 0.57 \\
& & {$[0.31,0.61]$} & {$[0.40,0.55]$} & {$[0.31,0.70]$} & {$[0.53,0.75]$} & {$[0.15,0.53]$} & {$[0.42,0.69]$} \\
AC6(RVol) & 0.37 & 0.12 & 0.22 & 0.13 & 0.28 & 0.14 & 0.25 \\
& & {$[0.04,0.23]$} & {$[0.17,0.26]$} & {$[0.04,0.23]$} & {$[0.18,0.45]$} & {$[0.03,0.32]$} & {$[0.15,0.43]$} \\
AC12(RVol) & 0.28 & 0.02 & 0.08 & 0.02 & 0.18 & 0.12 & 0.19 \\
& & {$[-0.06,0.12]$} & {$[0.05,0.12]$} & {$[-0.06,0.12]$} & {$[0.06,0.38]$} & {$[0.02,0.29]$} & {$[0.07,0.39]$} \\
\hline \hline
\end{tabular}



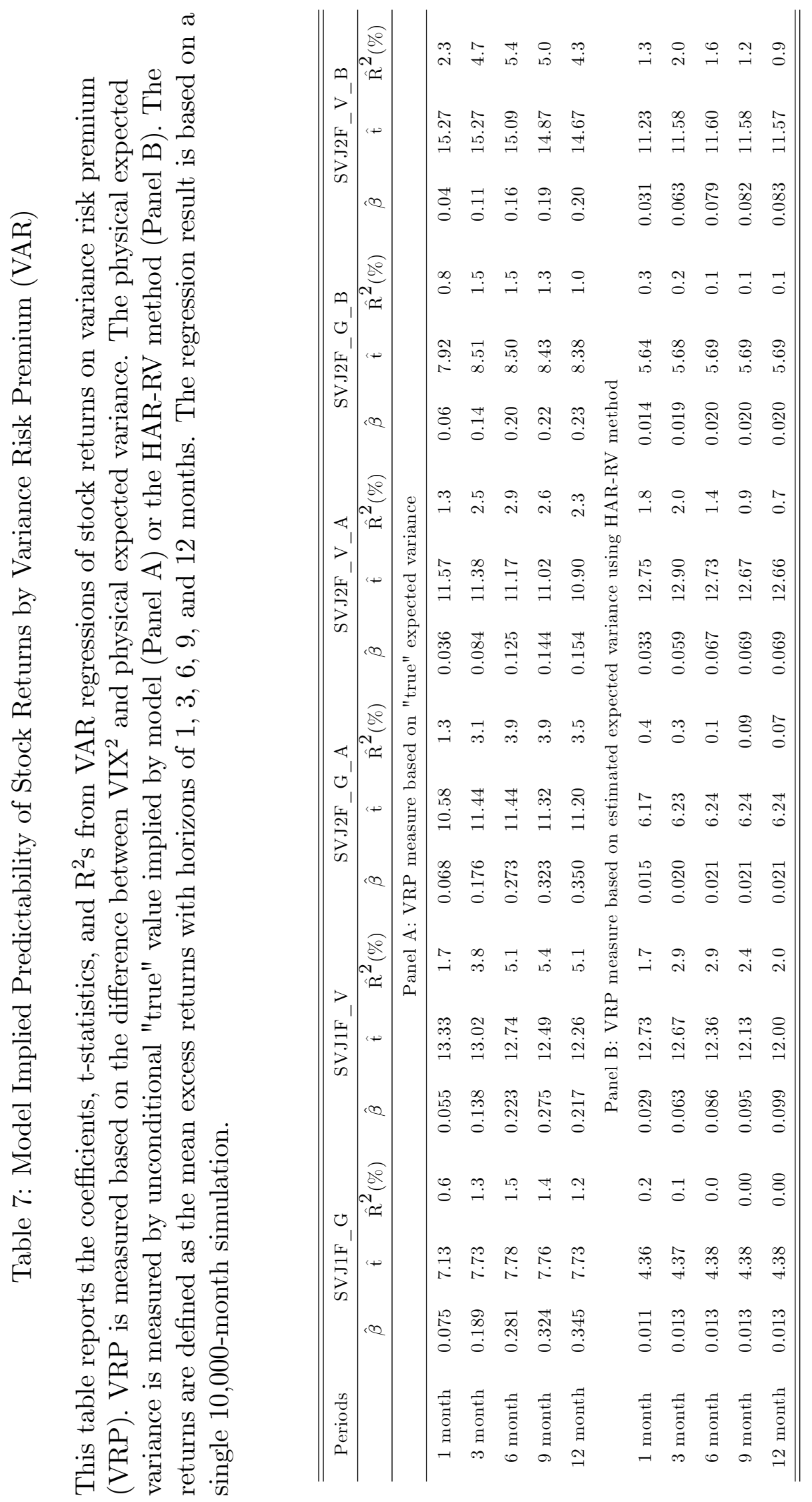


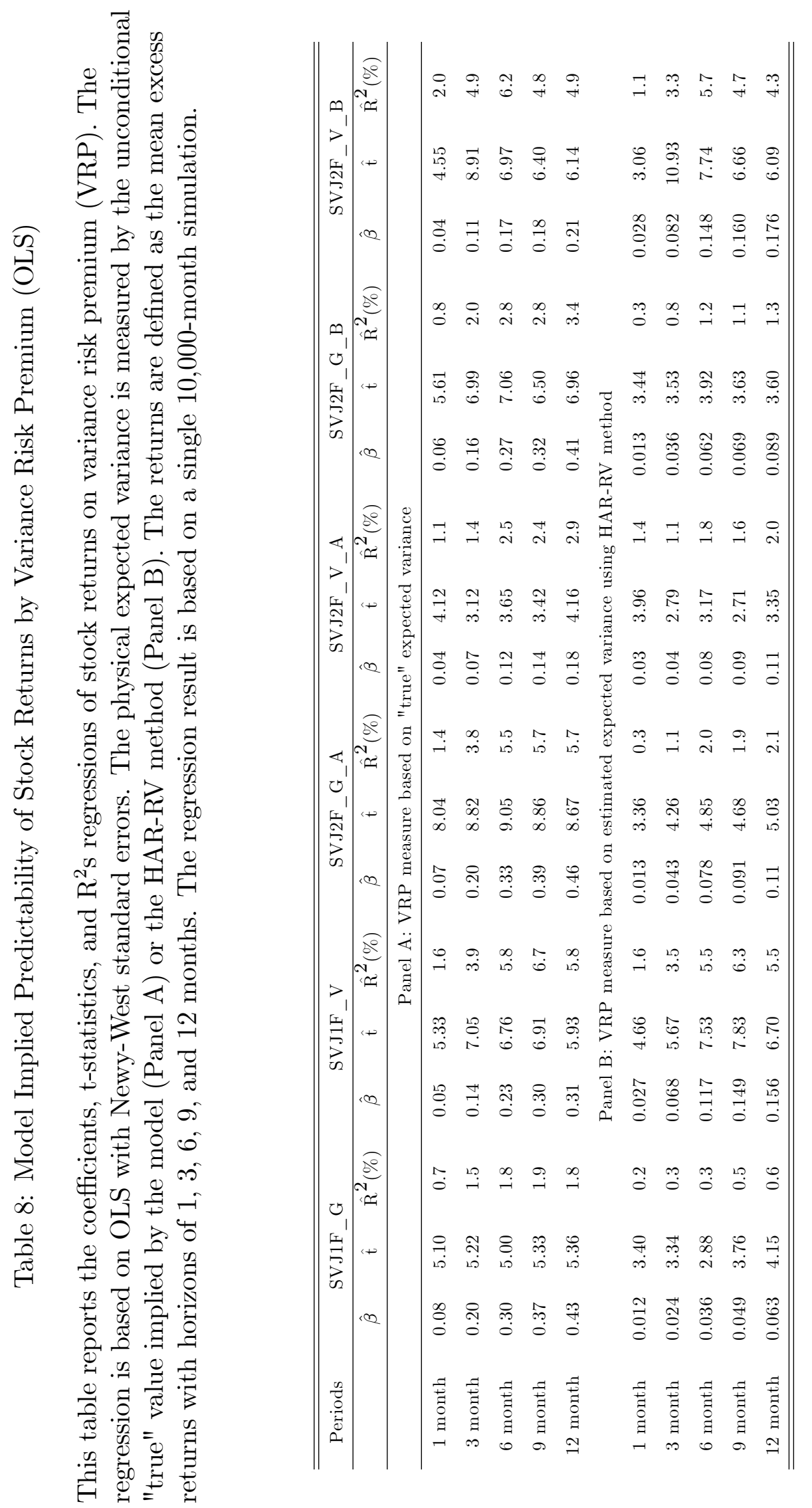




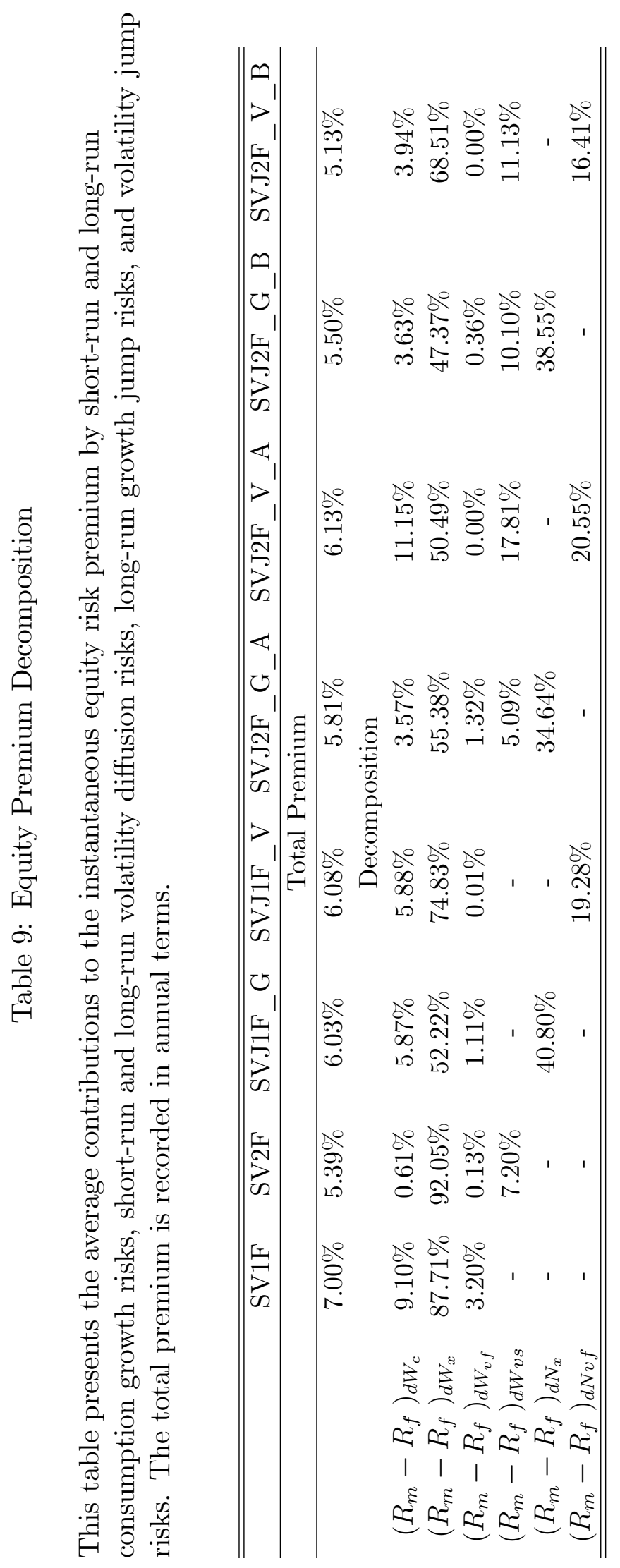




\section{Table 10: Comparison of Consumption and Dividend Growth Moments}

This table displays moment matches in annual US consumption and dividend growth The percentiles of the statistics are based on 1000 model simulations with each simulation spanning a period of 60 years.

\begin{tabular}{|c|c|c|c|c|c|c|c|}
\hline & data & SVJ1F_G & SVJ1F_V & SVJ2F_G_A & SVJ2F_V_A & SVJ2F_G_B & SVJ2F_V_B \\
\hline \multirow[t]{2}{*}{$E(\Delta c)$} & 2.03 & 2.09 & 2.05 & 2.03 & 2.06 & 2.06 & 2.03 \\
\hline & & {$[0.52,3.38]$} & {$[0.57,3.43]$} & {$[0.80,3.11]$} & {$[0.87,3.22]$} & {$[0.74,3.22]$} & {$[0.77,3.32]$} \\
\hline \multirow[t]{2}{*}{$\sigma(\Delta c)$} & 1.22 & 1.88 & 1.85 & 1.21 & 1.35 & 1.88 & 1.59 \\
\hline & & {$[1.45,2.55]$} & {$[1.45,2.48]$} & {$[0.88,1.83]$} & {$[1.04,1.87]$} & {$[1.34,2.70]$} & {$[1.15,2.31]$} \\
\hline \multirow[t]{2}{*}{ Skew. $(\Delta c)$} & -0.59 & -0.20 & -0.02 & -0.21 & -0.01 & -0.22 & 0.02 \\
\hline & & {$[-0.92,0.41]$} & {$[-0.83,0.73]$} & {$[-0.96,0.46]$} & {$[-0.82,0.89]$} & {$[-1.02,0.56]$} & {$[-0.70,0.77]$} \\
\hline \multirow[t]{2}{*}{ Kurt. $(\Delta c)$} & 3.47 & 2.99 & 2.92 & 2.89 & 3.14 & 2.91 & 2.82 \\
\hline & & {$[2.23,4.72]$} & {$[2.16,5.18]$} & {$[2.11,4.71]$} & {$[2.21,6.49]$} & {$[2.18,4.64]$} & {$[2.09,4.37]$} \\
\hline \multirow[t]{2}{*}{$A C 1(\Delta c)$} & 0.38 & 0.50 & 0.55 & 0.60 & 0.44 & 0.66 & 0.62 \\
\hline & & {$[0.25,0.71]$} & {$[0.30,0.74]$} & {$[0.31,0.81]$} & {$[0.17,0.67]$} & {$[0.42,0.81]$} & {$[0.35,0.80]$} \\
\hline \multirow[t]{2}{*}{$E(\triangle d)$} & 2.52 & 2.20 & 2.14 & 2.02 & 1.45 & 2.25 & 2.21 \\
\hline & & {$[-2.60,6.41]$} & {$[-2.66,6.68]$} & {$[-2.11,5.67]$} & {$[-3.13,5.84]$} & {$[-1.73,5.94]$} & {$[-0.02,0.06]$} \\
\hline \multirow[t]{2}{*}{$\sigma(\Delta d)$} & 12.52 & 8.05 & 7.74 & 7.13 & 11.68 & 6.97 & 6.31 \\
\hline & & {$[6.56,10.13]$} & {$[6.29,9.74]$} & {$[5.57,9.13]$} & {$[9.03,15.52]$} & {$[5.30,9.56]$} & {$[4.72,8.45]$} \\
\hline \multirow[t]{2}{*}{ Skew. $(\Delta d)$} & 0.18 & -0.19 & -0.08 & -0.17 & -0.07 & -0.15 & 0.00 \\
\hline & & {$[-0.92,0.50]$} & {$[-1.09,0.85]$} & {$[-0.96,0.62]$} & {$[-1.24,0.98]$} & {$[-0.83,0.58]$} & {$[-0.70,0.68]$} \\
\hline \multirow[t]{2}{*}{ Kurt. $(\Delta d)$} & 5.51 & 3.21 & 3.21 & 3.45 & 3.53 & 2.99 & 2.96 \\
\hline & & {$[2.34,5.37]$} & {$[2.31,7.08]$} & {$[2.44,5.68]$} & {$[2.46,8.00]$} & {$[2.23,4.55]$} & {$[2.24,4.32]$} \\
\hline \multirow[t]{2}{*}{$A C 1(\Delta d)$} & 0.35 & 0.36 & 0.40 & 0.32 & 0.26 & 0.51 & 0.45 \\
\hline & & {$[0.14,0.57]$} & {$[0.16,0.61]$} & {$[0.10,0.54]$} & {$[0.03,0.46]$} & {$[0.27,0.69]$} & {$[0.20,0.67]$} \\
\hline
\end{tabular}


Table 11: Predictability of Excess Returns, Consumption and Dividends

This table presents the coefficients, t-statistics, and $\mathrm{R}^{2} \mathrm{~s}$ imputed from the monthly data from 1951.1 to 2010.7. Panel A reports regressions of excess returns, consumption growth rates, dividend growth rates on log price-dividend ratios; Panel B reports regressions of stock return volatility, consumption volatility, and dividend volatility on lagged log price-dividend ratios. For excess return predictability, VAR analysis is used to deduce the t-ratio and $R^{2}$. $R^{2}$ is in percentage unit.

Panel A. Regressions of Returns, Consumption and Dividend Growth

\begin{tabular}{cccccccccc}
\hline \multicolumn{1}{c}{ excess return (VAR) } & \multicolumn{3}{c}{ consumption growth(OLS) } & \multicolumn{4}{c}{ dividend growth(OLS) } \\
\hline & $\hat{\beta}$ & $\hat{\mathrm{t}}$ & $\hat{\mathrm{R}}^{2}(\%)$ & $\hat{\beta}$ & $\hat{\mathrm{t}}$ & $\hat{\mathrm{R}}^{2}$ & $\hat{\beta}$ & $\hat{\mathrm{t}}$ & $\hat{\mathrm{R}}^{2}(\%)$ \\
\hline 12 months & -12.95 & -1.99 & 6.1 & 0.016 & 2.03 & 11.8 & 0.089 & 1.22 & 2.5 \\
36 months & -32.75 & -1.97 & 14.3 & 0.028 & 1.55 & 8.3 & 0.096 & 0.53 & 0.9 \\
60 months & -46.33 & -1.91 & 18.7 & 0.028 & 1.26 & 5.2 & 0.066 & 0.33 & 0.03 \\
\hline \hline
\end{tabular}

Panel B. Regressions of Volatilities of Stock Returns, Consumption Growth, and Dividend Growth

\begin{tabular}{cccccccccc}
\hline & \multicolumn{1}{c}{ realized volatility(OLS) } & \multicolumn{4}{c}{ consumption volatility(OLS) } & \multicolumn{3}{c}{ dividend volatility(OLS) } \\
\hline & $\hat{\beta}$ & $\hat{\mathrm{t}}$ & $\hat{\mathrm{R}}^{2}(\%)$ & $\hat{\beta}$ & $\hat{\mathrm{t}}$ & $\hat{\mathrm{R}}^{2}$ & $\hat{\beta}$ & $\hat{\mathrm{t}}$ & $\hat{\mathrm{R}}^{2}(\%)$ \\
\hline 12 months & -0.18 & -0.65 & 1.9 & -0.27 & -1.15 & 2.3 & -0.18 & -0.50 & 0.8 \\
36 months & -0.11 & -0.44 & 0.9 & -0.33 & -1.42 & 6.8 & -0.05 & -0.15 & 0.08 \\
60 months & -0.01 & -0.03 & 0.0 & -0.26 & -1.41 & 6.3 & 0.03 & -0.10 & 0.04 \\
\hline \hline
\end{tabular}




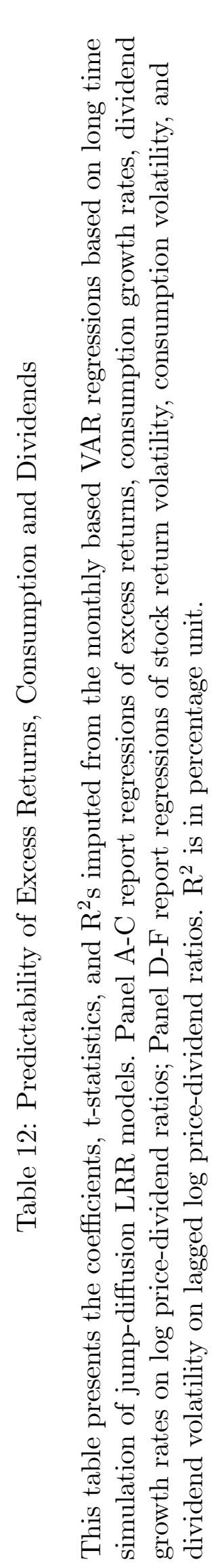

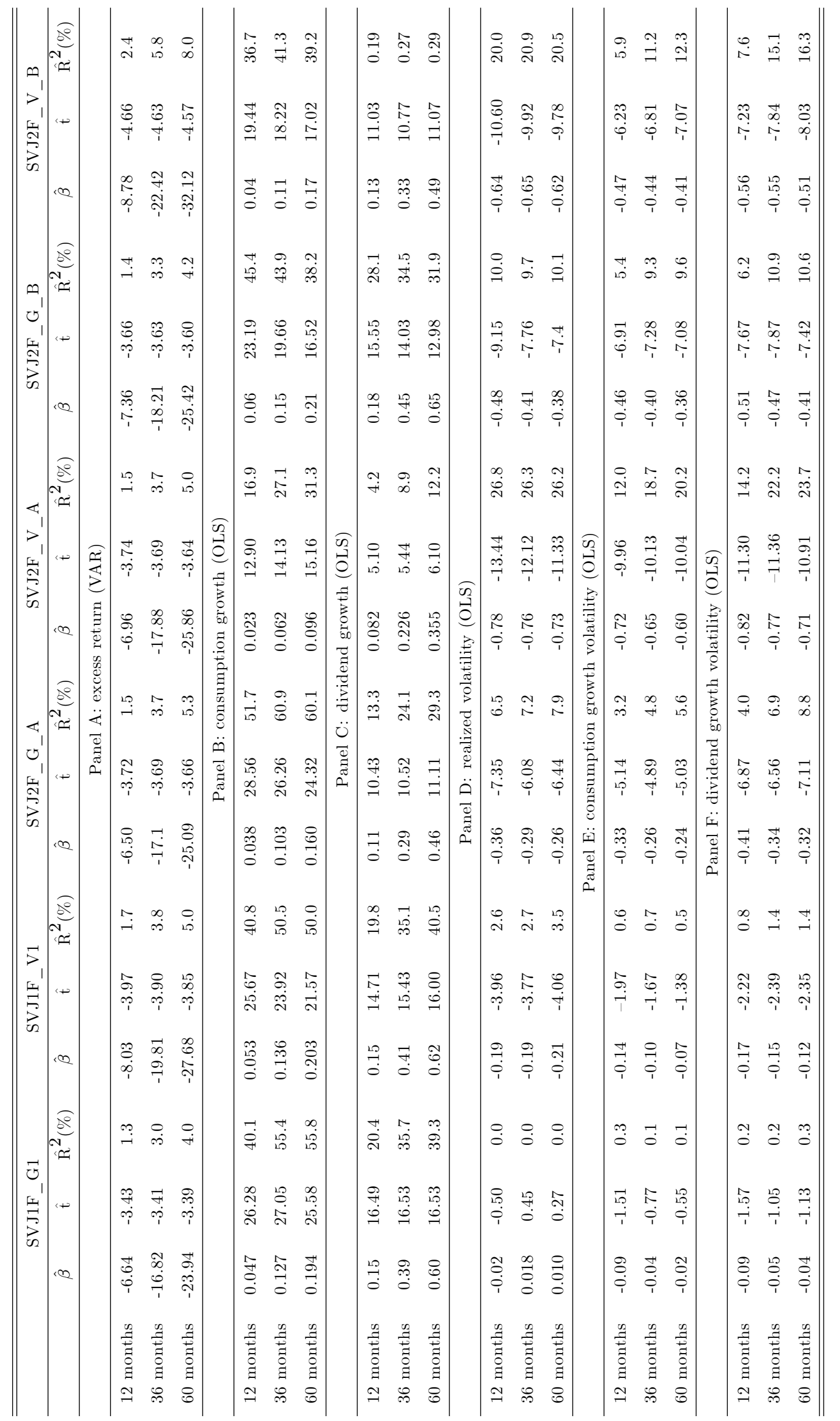


Figure 1: $\log$ P/D ratio with and without Stock Repurchase Adjustment

This figure illustrates the $\log \mathrm{P} / \mathrm{D}$ ratio based on cash dividend and adjusted with repurchase. Since the repurchase data is only available since 1971, the two series are the same before 1971. The $\log \mathrm{P} / \mathrm{D}$ ratio denotes the $\log$ of the ratio between the S\&P 500 index and the total dividend (including repurchase) paid over the last 12 months.

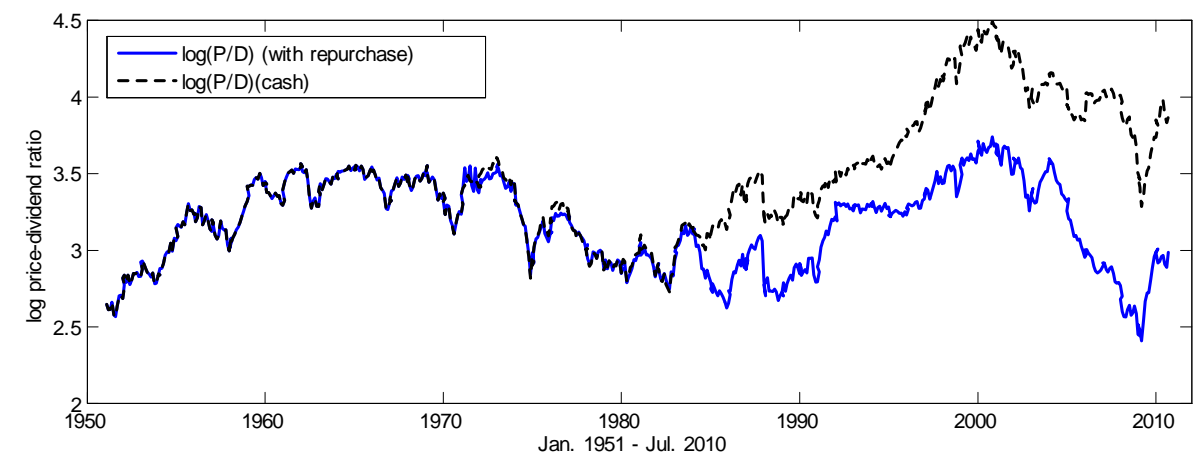

Figure 2: GDP Deflator and Consumption Price Index

This figure illustrates the quarterly GDP deflator and the consumer price index (CPI) from Q1:1951 to Q2:2010. The data is collected from the BEA

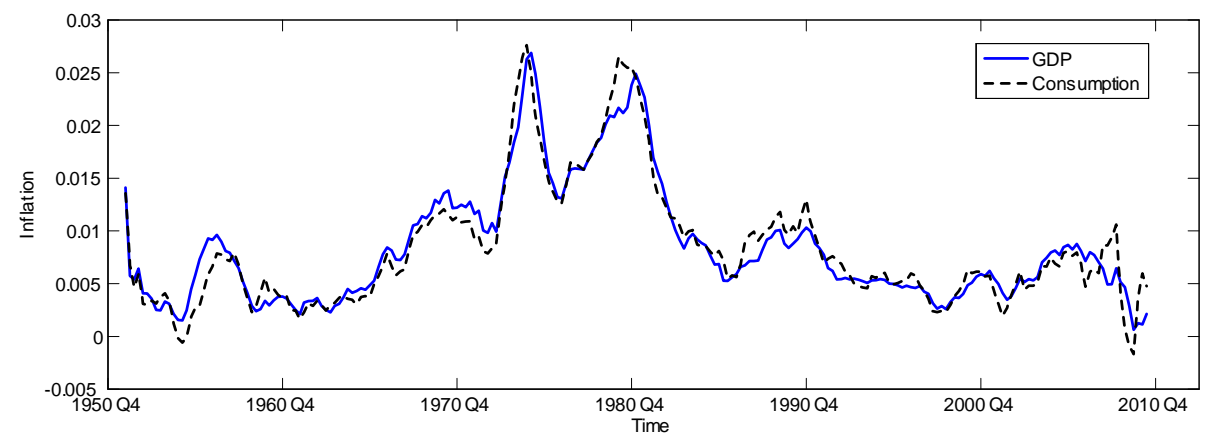


Figure 3: Empirical and Model-implied Risk-Neutral Expected Variance (VIX $\left.{ }^{2}\right)$ This figure illustrates the 1-month risk-neutral expected variance $\left(\mathrm{VIX}^{2}\right)$ and the model-implied values of the VIX ${ }^{2}$.

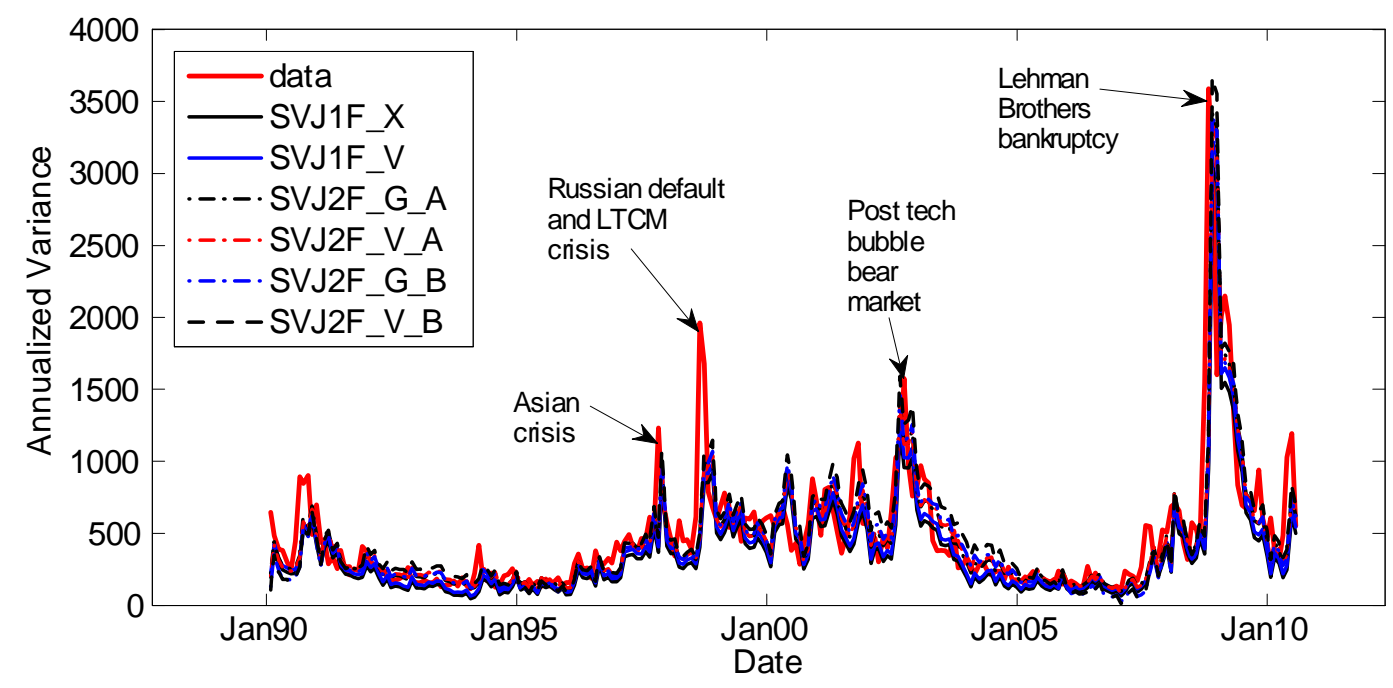

